\title{
A COMPUTER PROGRAM FOR THE \\ KINETIC TREATMENT OF RADIATION-INDUCED SIMULTANEOUS CHEMICAL REACTIONS
}

by

Klaus H. Schmidt

Chemistry, Division

April 1966

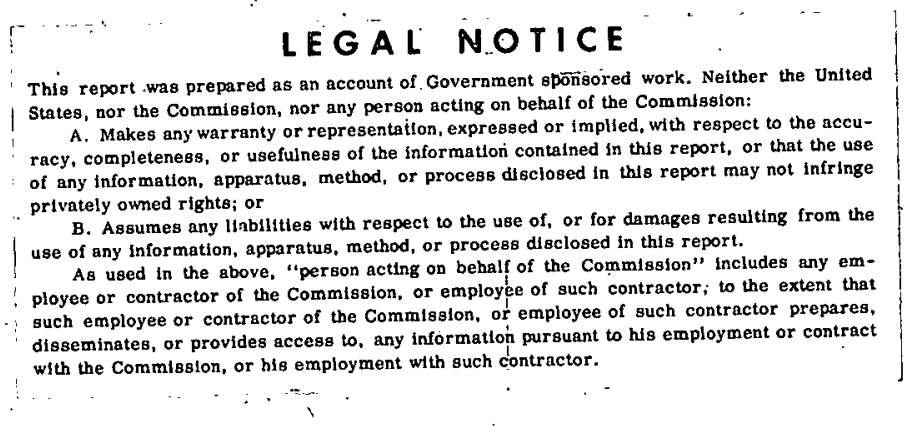

Operated by The University of Chicago under

Contract W-31-109-eng-38

with the

U. S. Atomic Energy Commission 


\section{DISCLAIMER}

This report was prepared as an account of work sponsored by an agency of the United States Government. Neither the United States Government nor any agency Thereof, nor any of their employees, makes any warranty, express or implied, or assumes any legal liability or responsibility for the accuracy, completeness, or usefulness of any information, apparatus, product, or process disclosed, or represents that its use would not infringe privately owned rights. Reference herein to any specific commercial product, process, or service by trade name, trademark, manufacturer, or otherwise does not necessarily constitute or imply its endorsement, recommendation, or favoring by the United States Government or any agency thereof. The views and opinions of authors expressed herein do not necessarily state or reflect those of the United States Government or any agency thereof. 


\section{DISCLAIMER}

Portions of this document may be illegible in electronic image products. Images are produced from the best available original document. 
TAB LE OF CONTENTS

Page

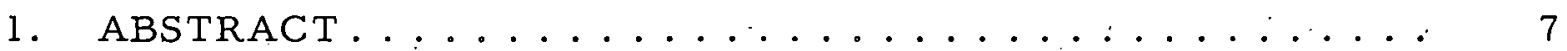

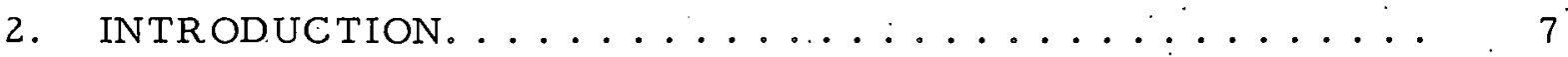

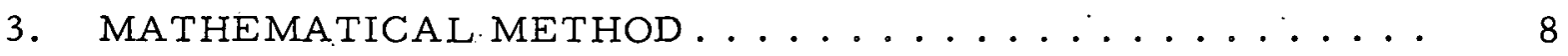

3.1 Setting Up Differential Equations.............. 8

3.2 Solving Differential Equations............... $9^{-}$

3.3 Automatic Determination of Time Increments--Accuracy .. 10

3.4 Options: Quasiequilibrium between Fast-reacting

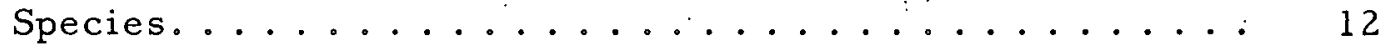

3.4.1 Principle of the Method............. 12

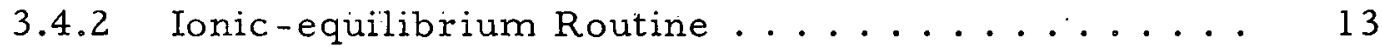

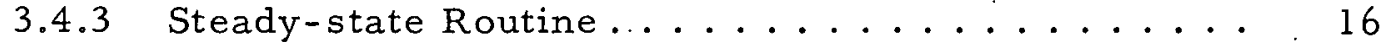

4. OTHER OPTIONS OF THE PROGRAM .............. 17

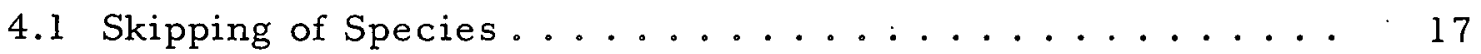

4.2 Skipping of Reactions ...................... 17

4.3 "Freezing" of Time Increments .............. 18

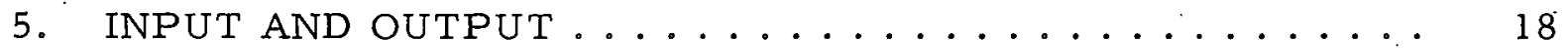

5.1 General Requirements and Format of Input......... 18

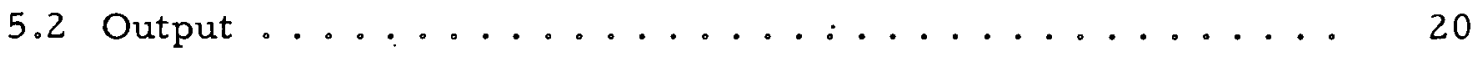

6. SUGGESTIONS FOR THE USE OF THE PROGRAM . . . . . . . 24

6.1 Application of the Program in Special Cases . . . . . . 24

6.i.l First-order Reactions.............. 24

6.1.2 Third-and.Fourth-order, Pseudo Second-order

Reactions ..................... 24

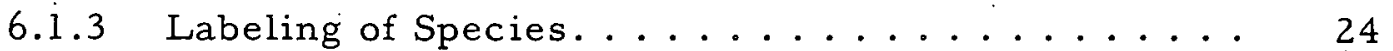

6.1.4 Photochemical Reactions........... 25

6.1.5 Calculations of Other Linear Combinations of

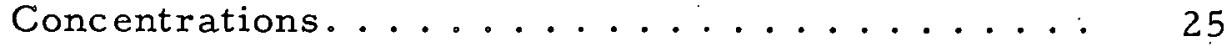

6.1.6 Reactions with More Than Four Products...... 26

6.2 Special Error Messages and Countermeasures ....... 26

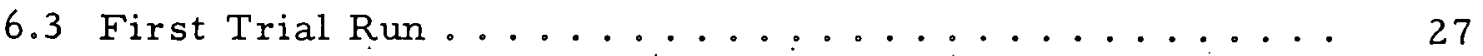


TAB LE OF CONTENTS

$\underline{\text { Page }}$

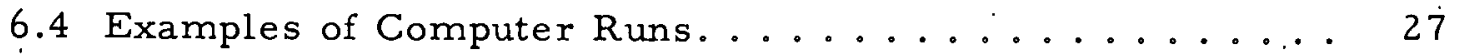

6.4.1 Example 1: Pulse Radiolysis of Pure Degassed

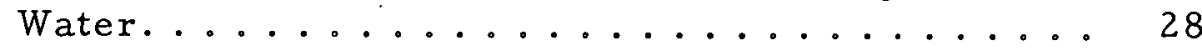

6.4.2 Example 2: Decay Products of Radon ....... 28

6.4.3 Example 3: Removal of Traces of Oxygen from Hydrogen-saturated Water by Preirradiation with

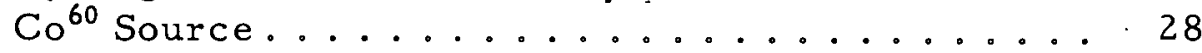

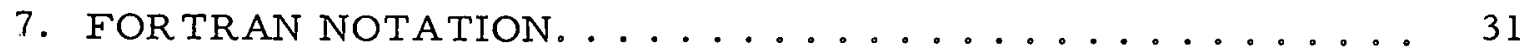

8. LISTING OF FORTRAN SOURCE DECKS .......... 35

9. APPENDIX: Modification of the Program for use. with an

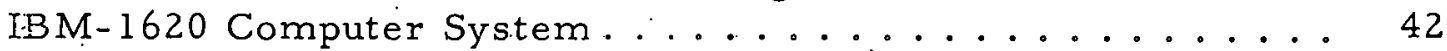

9.1 Required Program and Subroutines ............. 42

9.2 Suggested Operating Procedure............. 42

9.3 Restrictions and Additional Features of Program WRl 7

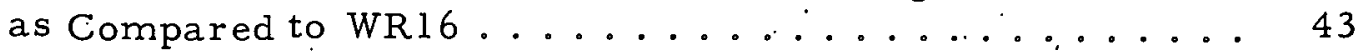

9.4 FORTRAN Notation and Listing of Source Decks . . . . 44

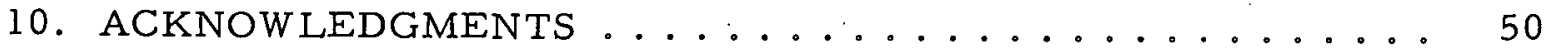

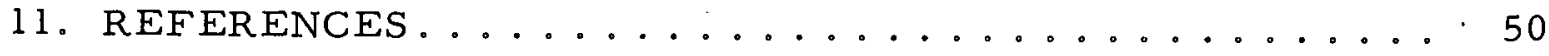




\section{LIST OF FIGURES}

No.

1. "Link" Routine after Doubling of Time Increments . . . . . 12

2. Format of Input Data. ................... 14

3. Mathematical Model for the Pulse Radiolysis of Pure

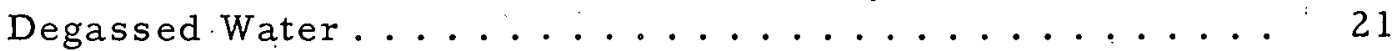

4. Calculation of the $\beta$ Emission of Radon and its Decay

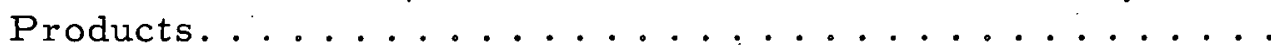

5. Mathematical Model for the Deoxygenation of Water by

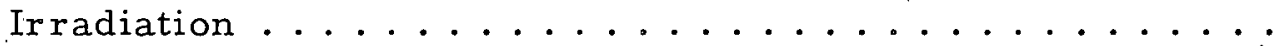

6. Control Cards for Executing Program WR17........

7. Example of a Typewriter Printout Obtained by Turning on

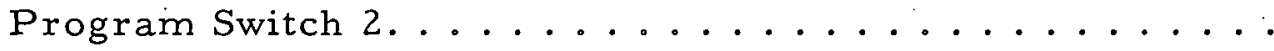

\section{LIST OF TABLES}

No.

I. Values of $\beta_{\mathrm{pm}} \ldots \ldots \ldots \ldots \ldots \ldots$

II. FORTRAN Notation in WR16 and Subroutines........ 32

III. FORTRAN Notation for WRl 7 and Subroutines as Far as

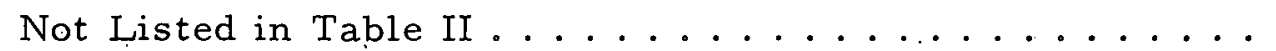


A COMPUTER PROGRAM FOR THE

KINETIC TREATMENT OF RADIATION-INDUCED

SIMULT ANEOUS CHEMIC AL REACTIONS

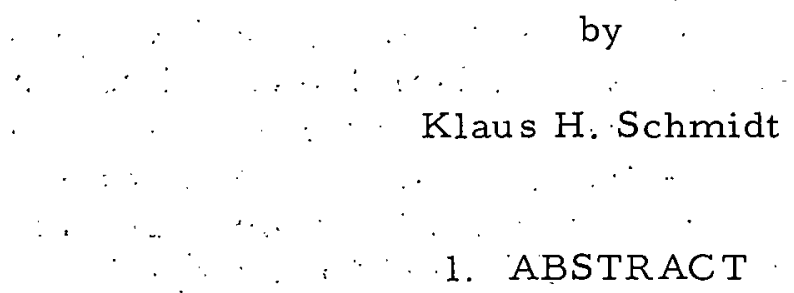

WR 16,* a program written in 3600-FORTRAN for a CDC-3600 digital computer, calculates, as a function of time, the concentrations of all the species taking part in the simultaneous first- and second-order chemical reactions occurring during and after exposure to ionizing radiation of any chemical system (for example, an aqueous solution). Homogeneous reaction kinetics is assumed for the computation. The variation of electrical conductivity and optical absorbance of the system can also be: computed.

As data, the program requires the chemical reaction equations with rate constants, a list of the species involved. with their radiation.yields, rates of spontaneous formation (if any), initial concentrations, equivalent conductances and molar absorptivities, and the dose rate and duration of ir radiation.

A simplified version of the program, adapted for an IBM-1620 computer system, is also included.

\section{INTRODUCTION}

The computer program presented in this report was developed to provide the radiation chemist with a tool to evaluate his experimental findings. Radiation chemistry experiments usually yield as results the amounts of one or several products formed, or the variation of some physical quantity (e.g., optical absorbance or electrical conductivity) during and/or after irradiation. In the latter case, irradiation is mostly applied in the form of short pulses ("pulse radiolysis").

A possible way to evaluate the results is to construct a model sys- tem including all the reactions known or assumed to be significant, using.

\footnotetext{
* "WR" stands for "Water Radiolysis," the mathematical treatment of which necessitated the development of this program.
} 
for rate constants, yields, etc., known values as far as available, and assumed or estimated values for the yet unknown quantities, and to compare the measured values with the corresponding quantities calculated for the model system.

Program WR 16 makes it possible to set up, and investigate the properties of, such model systems of even considerable complexity in a simple way, since the chemical reaction equations themselves are entered as data, thus eliminating the necessity of setting up a new system of differential equations for every model. Apart from radiation chemistry, the program can be used for the treatment of other reaction-kinetic systems including radioactive decay schemes.

For users who have no access to a CDC-3600 computer but have available an IBM-1620 computer system, a somewhat less versatile version of this program, written in FORTRAN II-D for a system consisting of an IBM-1620 computer with a 40-k memory in connection with an IBM- 1620 Monitor-II system,* is described in an appendix.

\section{MATHEMATICAL METHOD}

\subsection{Setting Up Differential Equations}

Let the chemical reaction scheme consist of $n_{\dot{r}}$ reactions of the following type:

$$
A_{1 i}+A_{2 i} \stackrel{k_{i}}{\rightarrow} A_{3 i} \pm * A_{4 i} \pm A_{5 i} \pm A_{6 i} ; \quad i=1, \ldots, n_{r}
$$

where the species $A_{m i}, m=1, \ldots, 6$, need not all. be different from each other, and where there may be less than four species on the right side of the equation, and $k_{i}$ is the second-order rate constant for the reaction of $A_{1 i}$ with $A_{2 i}$. Let, furthermore, $A_{1}^{i}, A_{2}^{\prime}, \ldots, A_{n_{c}}^{\prime}$ denote all the species involved in the reaction scheme: Then the following set of differential equations can be derived:

$$
\frac{d c_{j}}{d t}=\frac{1}{100 N_{a}} G_{j} I+s_{j}^{\prime}+\sum_{i=1}^{n_{r}} \alpha_{j i} k_{i} c_{1 i}^{\prime} c_{2 i}^{\prime} ; \quad j=1, \ldots, n_{c},
$$

where $c_{j}$ is the concentration of $A_{j}^{\prime}, c_{m i}^{i}$ that of $A_{m i}, N_{a}$. is Avogadro's number $\left(\mathrm{N}_{\mathrm{a}}=6.0231^{\prime} \times 10^{23}\right), \mathrm{G}_{\mathrm{j}}$ is the radiation yield in particles per $100 \mathrm{eV}$, .I is the dose rate in eV/l-sec, $s_{j}^{\prime}$ is the rate of spontaneous formation (e.g., in the case of $\mathrm{H}_{\mathrm{aq}}^{+}$and $\left.\cdot \mathrm{OH}_{\mathrm{aq}}^{-}\right)$, and the $\alpha_{j i}$ are integral constants.

*If only a Monitor-I system is available, a 60-k memory is required. 
The program compares the species (Holerith words) $A_{m i}$ with the $A_{j}^{\prime}$ and calculates the matrix $\left(\alpha_{j i}\right)$ as follows.

$$
\alpha_{j i}=-\delta_{j}^{1 i}-\delta_{j}^{2 i}+\delta_{j}^{3 i}+\sum_{m=4}^{6} \sigma_{m i} \delta_{j}^{m i} ;, j=1, \ldots, n_{c} ; . i=1, \ldots, n_{r},
$$

where $\sigma_{\mathrm{mi}}$ is the sign * of $A_{\mathrm{mi}}$, and

$$
\delta_{j}^{m i}=\left\{\begin{array}{l}
1 \text { if } A_{j}^{\prime}=A_{m i} \\
0 \text { if } A_{j}^{\prime} \neq A_{m i}
\end{array}\right.
$$

\subsection{Solving Differential Equations:}

The following abbreviations will be used:

$$
\begin{aligned}
& \dot{\mathrm{c}}_{j}=\frac{d c_{j}}{d t} ; \quad g_{j}=\frac{1}{100 N_{a}} G_{j} I+s_{j} ; \quad a_{j i}=\alpha_{j i} k_{i} ; \\
& f_{j}(\underline{c})=f_{j}\left(c_{1}, c_{2}, \ldots, c_{n_{c}}\right)=g_{j}+\sum_{i} a_{j i} c_{i i}^{\prime} c_{2 i} .
\end{aligned}
$$

Thus, for the-differential equations

$$
\dot{c}_{j}=f_{j}(\underline{c}) ; \quad j=1, \ldots, n_{c} \text {, }
$$

we have to find solutions $c_{j}(t)$ with. $c_{j}(0)=\gamma_{j}$. This is accomplished by the program by applying a modification of Adam's extrapolation method. ${ }^{1}$

If $t_{1}, t_{2}, \ldots, t_{n}$ are equidistant points on the time axis with the in crement $\tau$, then approximate solutions $c_{j}(\mathrm{p})(\mathrm{t})$ are computed as follows:

$$
c_{j}^{(p)}\left(t_{n+1}\right)=c_{j}^{(p)}+\tau \sum_{m=1}^{p} \beta_{p m} \cdot f_{j}\left[\underline{c}^{(p)}\left(t_{n-m+1}\right)\right]
$$

where $p$ denotes the order of approximation and the $\beta_{\mathrm{pm}}$ are the constants listed in Table 1. For all $t_{n} \cdot$ with $n \geq 5, p=5$ is used; for $n<5, p:=n$. The time increments are determined automatically by the program (see. Sect. 3.3).

If the dose rate is not constant, the total time range can be divided into $n_{t}$ time intervals $\left(T_{k-1} \leq t<T_{k}\right)$ with different values for $I$. In each time interval, the calculation restarts with $n:=1$. In the first time interval $t_{1}=0$ and $c_{j}^{(p)}\left(t_{1}\right)=\gamma_{j}$.

* The signs are usually plus. (t), but in special cases (see sect.'6.1.2) minus (-) signs may be formally used. 
TABLE I." Vialues of: $\beta$ pm

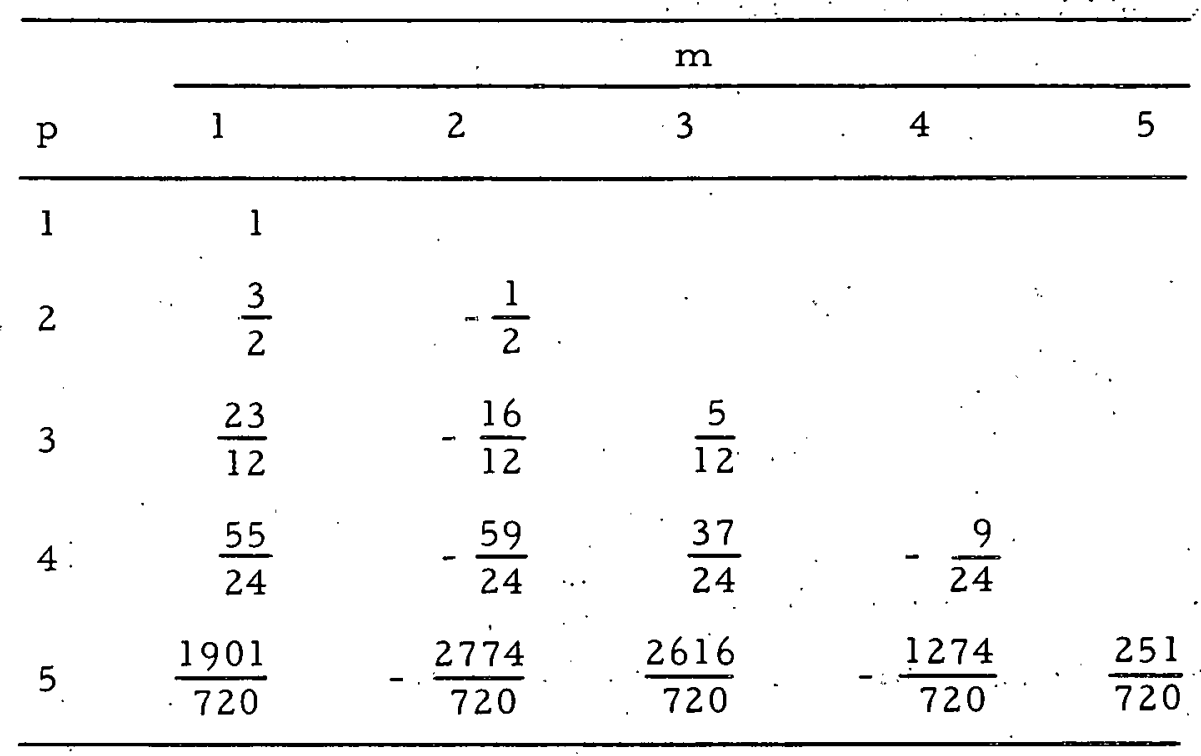

\subsection{Automatic Determination of Time Increments--Accuracy.}

Since the concentrations of the species involved in chemical reactions and the rate constants of such reactions may vary within a range of. many orders of magnitude, it was desirable to find a suitable quantity from which to determine the time increments $\tau$. Such a quantity can be found by the following considerations.

In Adam's extrapolation formula' the error term is

$$
\left|\Delta \epsilon_{j}\right| \leq b_{p}{ }^{p+1}\left|\frac{d^{p_{f_{j}}(c)}}{d t^{p}}\right| ;
$$

where $\Delta \epsilon_{j}$ is the error increment of $c_{j}$ for one step $\tau$ (error propagation not included), $b_{p} \leq 1 / 2$ for $p \leq 5$. At the same time, the increment of $c_{j}$ is approximately

$$
\Delta c_{j} \approx \tau f_{j}(\underline{c})
$$

Thus

$$
\left|\frac{\Delta \epsilon_{j}}{\Delta c_{j}}\right| \leq b_{p} \tau\left|\frac{d^{p+i} c_{j} / d t p}{f_{j}(\underline{c})}\right|=b_{p} \tau\left|\frac{d^{p+1} c_{j} / d t p}{d c_{j} / d t}\right| .
$$

Therefore, the quantity

$$
\mathrm{R}_{\mathrm{j}}^{(\mathrm{p})}(\mathrm{t})=\frac{1}{2} \tau\left|\frac{\mathrm{d}^{\mathrm{p}+1} \mathrm{c}_{\mathrm{j}} / \mathrm{dt} \mathrm{P}}{\mathrm{dc}_{\mathrm{j}} / \mathrm{dt}}\right|
$$


can be regarded as a suitable measure for the accuracy of computation at a given time $t$. Now, for a differential equation of the form

$$
\stackrel{\xi}{c}_{j}=E_{j}-\dot{F}_{j} c_{j}
$$

it can easily be shown that

$$
R_{j}^{(p)}=\frac{1}{2} F_{j}^{p_{T}} p=\frac{1}{2}\left(\frac{T}{T_{j}}\right)^{p}
$$

since $T_{j}=1 / F_{j}$ is the lifetime of the $j$-th species in this case, i.e., the accuracy depends on the ratio of time increment and lifetime. The actual differential equation

$$
\ddot{\mathbf{c}}_{j}=f_{j}(\underline{c})
$$

can be approximated within a small domain around any point $c^{*}=$ $\left(c_{1}^{*}, \ldots, c_{n_{C}}^{*}\right)$ by

$$
\begin{aligned}
\dot{c}_{j} & =f_{j}\left(\underline{c}^{*}\right)+\sum_{k=1}^{n_{c}} \frac{\partial f_{j}}{\partial c_{k}}\left(c_{k}-c_{k}^{*}\right) \\
& =\left\{f_{j}\left(c^{*}\right)+\sum_{k=j} \frac{\partial f_{j}}{\partial c_{k}}\left(c_{k}-c_{k}^{*}\right)-\frac{\partial f_{j}}{\partial c_{j}} c_{k}^{*}\right\}+\frac{\partial f_{j}}{\partial c_{j}} c_{j}
\end{aligned}
$$

If $A_{j}^{\prime}$ is the species with the shortest lifetime; then in practically all cases the term in braces will be sufficiently constant and thus represent. $E$.' Since $\partial f_{j} / \partial c_{j}<0$, we obtain the (time-dependent) "lifetime"

$$
T_{j}=1 / F_{j}=-1 /\left(\partial f_{j} / \partial c_{j}\right) \text {. }
$$

According to these considerations, the program determines the required time increment $\tau_{\mathrm{r}}$ as follows.

$$
\frac{\partial f_{j}}{\partial c_{j}}=\sum_{i=1}^{n_{r}} \alpha_{j i} k_{i}\left(c_{1 i}^{\prime} \delta_{j}^{2 i}+c_{2 i}^{\prime} \delta_{j}^{1 i}\right) ; \quad \tau_{r}=q / \max _{j}\left(\left|\partial f_{j} / \partial c_{j}\right|\right)
$$

where q is an empirical "accuracy factor" which may be entered with the data. If no value is entered, the program will use $q=0.05$, which value is appropriate in practically all cases.

After every 20 time increments the actual value of $\tau$ is compared with $\tau_{\mathbf{r}}$. If $\tau>1.4 \dot{\tau}_{\mathrm{r}}$, it is decreased by a factor of 2 ; if: $\tau<0.7 \tau_{\mathbf{r}}$, it is increased by the same factor. 
Whenever $\tau$ has been decreased, the calculation restarts with $n=1$ (i.e., $p=1$ ), since the method"used requires equidistant time values. When $\tau$ has been increased, some of the pre-

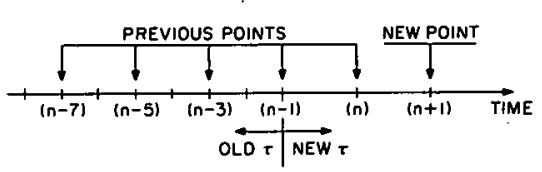

Fig. 1. "Link" Routine after Doubling of Time Increments vious points are skipped during the first 4 cycles ("link routine") so that only equidistant points enter the calculation. This is illustrated in Fig. 1.

For the first 20 cycles, the program uses as time increment a value $\tau_{\min }$ which may be entered with the data. Otherwise a suitable trial value is chosen by the program (see Sect. 5.1). $\tau_{\min }$ is the lower limit for $\tau$. An upper limit $\tau_{\max }$ may also be predetermined.

Although the described procedure for the determination of $\tau$ is far from exact in the mathematical sense, it has proven quite satisfactory for a variety of widely different schemes of chemical reactions. In practice, an accuracy factor of 0.05 or even 0.1 is sufficient in many cases to yield values with all four printed digits exact. In general, the results are very accurate up to a certain size of the time increments, but a slight further increase will cause divergence, and therefore completely and obviously erroneous results. This observed behavior is consistent with the errordetermining factor $(\tau / \mathrm{T}) \mathrm{P}$.

\subsection{Options: Quasiequilibrium between Fast-reacting Species}

\subsubsection{Principle of the Method}

In many reaction-kinetic systems, the fast-reacting species will soon reach a quasisteady state, i.e., in spite of high rates of formation and decay, the net rate of change of their concentrations will be very small and. of the same order of magnitude as that of the slowly reacting species. Since the required time increments are determined by the rate of decay of the fastest-reacting species, the total (model) time range for the calculation will be very large compared to the time increments used, so that such calculations would require long computing times (often considerably more than the usual time limit of $10 \mathrm{~min}$ ). For such cases, two options have been added to the program which allow treatment of the quasiequilibrium of the fast-reacting species separately. One option was especially designed for the equilibria of ionic species, whereas the other is of more general applicability. The common principle of both options is the following.

Let $\underline{c}^{n}=\left(c_{1}^{n}, c_{2}^{n}, \ldots, c_{n_{n}}^{n}\right)$ denote the concentrations of the species treated normally and $\underline{c} \underline{c}^{e}=\left(c_{1}^{e} ; c_{2}^{e}, \ldots, c_{n_{e}}^{e}\right)$ those of the species treated by the equilibrium routine. Then we can set up the equation system 


$$
\begin{aligned}
& \ddot{c}_{j}^{n}=f_{j}\left(\underline{c}^{n}, \underline{c}^{e}\right), \quad j=1, \ldots, n_{n} \\
& c_{k}^{e}=\phi_{k}\left(\underline{c}^{n}\right), \quad k=1, \ldots, n_{e} \text {, } \\
& \left(n_{n}+n_{e}=n_{c}\right) .
\end{aligned}
$$

where the functions $\phi_{\mathrm{k}}$ are derived from the steady-state conditions applied in either or both of the options. Let $\mathrm{c}^{*}$ and $\mathrm{c}^{*}$ be the concentrations at a time $t^{*}$. If $\tau_{e}$ is a time increment, approximate solutions $\tilde{c}_{j}$ for the time $t^{*}+\tau_{e}$ can be obtained by solving the set of equations

$$
\dot{\widetilde{c}}_{j,}^{n}=f_{j}\left(\widetilde{c}^{n}, \underline{c}^{*}\right) \text { with } \widetilde{c}_{j}^{n}\left(t^{*}\right)=c_{j}^{n}\left(t^{*}\right)
$$

for the interval $t^{*} \leq t \leq t^{*}+T_{e}$ in the way described in Sects. 3.2 and 3.3 , and then "adjusting" the concentrations $\mathrm{c}_{\mathrm{k}}^{\mathrm{e}}$ by means of the equations

$$
c_{k}^{e}\left(t^{*}+\tau_{e}\right)=\phi_{k}\left[c^{n}\left(t^{*}+\tau_{e}\right)\right]
$$

This procedure is repeated after every 20 time increments $\tau$, i.e., $\tau_{e}=20 \tau$. For the error introduced by this method one can derive the equation

$$
\frac{\Delta \epsilon_{j}^{e}}{\tau_{j}} \approx-\tau_{e} \sum_{k, 11} \frac{\partial f_{j}}{\partial c_{k}^{e}} \frac{\partial \phi_{k}}{\partial c_{i 11}^{n}} f_{m}
$$

where $\Delta \epsilon_{j}^{e}$ is the error increment for the concentration $c_{j}^{n}$ per time increment. $\tau_{e}$ (not including error propagation and the error produced by the normal routine).

This equation shows that the error at any given time is approximately proportional to the time increment $\tau_{e}$. It can be used to check the feasibility of using one of the equilibrium options, especially since normally most of the terms of the sum are zero. Usually the trial method consisting of two runs with different time increments is more practical.

\subsubsection{Ionic-equilibrium Routine}

The calculations in this routine are based on a set of equilibrium equations of the type

$$
\begin{array}{ll}
\mathrm{H}^{+}+\mathrm{HA}_{\mathrm{i}}^{-} \rightleftharpoons \mathrm{H}_{2} \mathrm{~A}_{\mathrm{i}}, & \left(\mathrm{K}_{1 \mathrm{i}}\right) \\
\mathrm{H}^{+}+\mathrm{A}_{\mathrm{i}}^{-} \rightleftharpoons \mathrm{HA}_{1}^{-}, & \left(\mathrm{K}_{2 \mathrm{i}}\right),
\end{array}
$$

where $i=1, \ldots, n_{e q}$ is a numbering index, $K_{1 i}$ and $K_{2 i}$ are the dissociation constants 


$$
\mathrm{K}_{1 \mathrm{i}}=\frac{\left[\mathrm{H}^{+}\right]\left[\mathrm{HA}_{\mathrm{i}}^{-}\right]}{\left[\mathrm{H}_{2} \mathrm{~A}_{\mathrm{i}}\right]} ; \quad \mathrm{K}_{2 \mathrm{i}}=\frac{\left[\mathrm{H}^{+}\right]\left[\mathrm{A}_{\mathrm{i}}^{\overline{1}}\right]}{\left[\mathrm{HA}_{\mathrm{i}}^{-}\right]}
$$

The equilibrium equations with their dissociation constants are entered with the data in the form shown in Fig. 2. They are read in by $a$. special subroutine (EQUILl). The calculation is performed by another subroutine (EQUIL2). One can easily derive the equations

$$
\begin{aligned}
& \left.\begin{array}{rl}
{\left[\mathrm{H}_{2} \mathrm{~A}_{\mathrm{i}}\right]} & =\frac{\mathrm{C}_{\mathrm{Ti}}}{1+\frac{\mathrm{K}_{\mathrm{ii}}}{\left[\mathrm{H}^{+}\right]^{*}}+\frac{\mathrm{K}_{1 \mathrm{i}} \mathrm{K}_{2 \mathrm{i}}}{\left[\mathrm{H}^{+}\right]^{* 2}}} \\
{\left[\mathrm{HA}_{\mathrm{i}}^{-}\right]} & =\mathrm{K}_{1 \mathrm{i}}\left[\mathrm{H}_{2} \mathrm{~A}_{\mathrm{i}}\right] /\left[\mathrm{H}^{+}\right]^{*} \\
{\left[\mathrm{~A}_{\mathrm{i}}^{-}\right]} & =\mathrm{K}_{2 \mathrm{i}}\left[\mathrm{HA}_{\mathrm{i}}^{-}\right] /\left[\mathrm{H}^{+}\right]^{*}
\end{array}\right\} \quad 1, \ldots, \mathrm{n}_{\mathrm{eq}} ; \\
& {\left[\mathrm{H}^{+}\right]=\left[\mathrm{H}^{+}\right]^{*}+\sum_{\mathbf{i}}\left(2\left[\mathrm{~A}_{\mathrm{i}}^{\overline{-}}\right]+\left[\mathrm{HA}_{\mathrm{i}}^{-}\right]\right)-\sum_{\mathrm{k}} \mathrm{Q}_{\mathrm{k}} \mathrm{c}_{\mathrm{k}}^{*}}
\end{aligned}
$$

The term $\sum_{\mathrm{k}} \mathrm{Q}_{\mathrm{k}} \mathrm{c}_{\mathrm{k}}^{*}$ represents the sum of the concentrations of all species except the $\mathrm{HA}_{\mathbf{i}}^{-}$and $\mathrm{A}_{\mathbf{i}}^{\bar{*}}$, multiplied by their charge's.

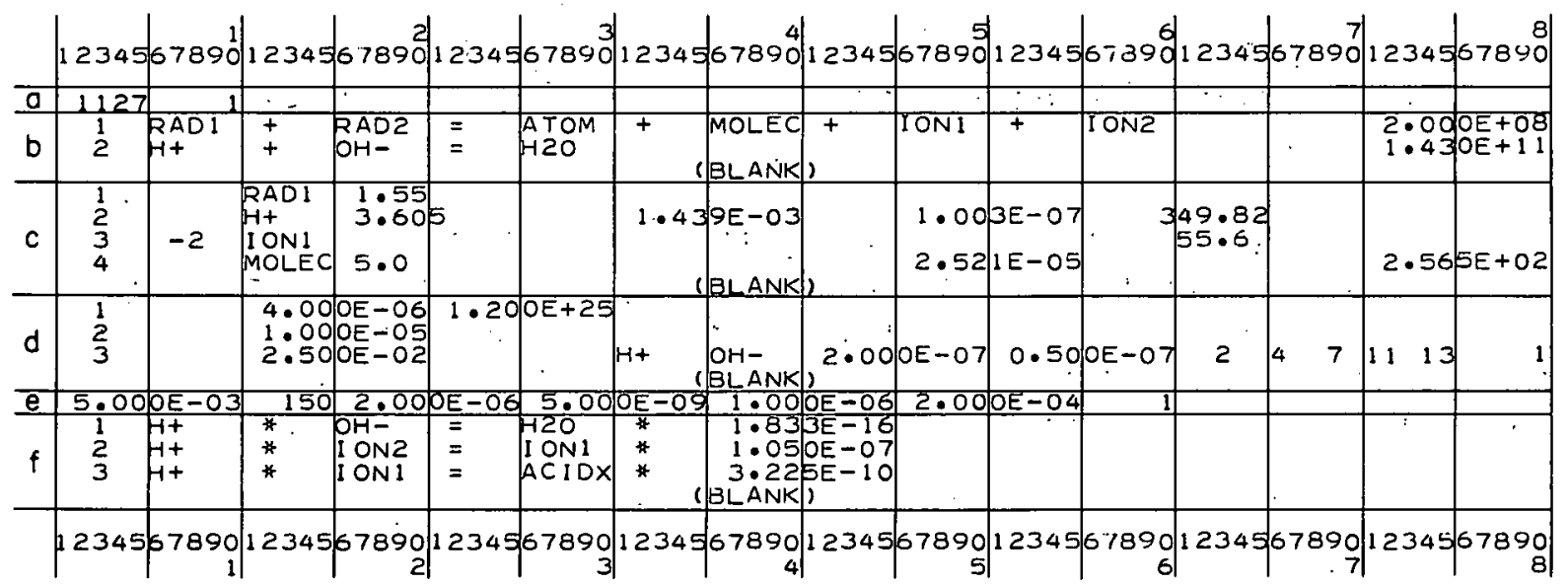

Fig. 2. Format of Input Data. The data shown represent no actual calculation and are only correct in regard to format.

The concentrations marked by asterisks (*) are the values obtained by the computer at the time $\mathrm{t}^{*}+\tau_{\mathrm{e}}$ before the new equilibrium is calculated, and

$$
\dot{C}_{\mathrm{Ti}}=\left[\mathrm{A}_{\mathrm{i}}^{\overline{\bar{j}}}\right]^{*}+\left[\mathrm{HA}_{\mathrm{i}}^{-}\right]^{*}+\left[\mathrm{H}_{2} \mathrm{~A}_{\mathrm{i}}\right]^{*}
$$


denotes the total amount of the acid $\mathrm{H}_{2} \mathrm{~A}_{\mathbf{i}}$ regardless of its state of dissociation. $\mathrm{C}_{\mathrm{Ti}}$ is one of the "species" named $\mathrm{c}_{\mathrm{j}}^{\mathrm{n}}$ in Sect. 3.4.1.

If only one state of dissociation exists, $K_{2 i}$ is set equal to zero.

The new equilibrium is now computed by using the se equations in a fast-converging iteration procedure which consists in solving an equation of the form

$$
\left[\mathrm{H}^{+}\right]=F\left(\left[\mathrm{H}^{+}\right]\right)
$$

by calculating the sequence

$$
\begin{aligned}
& \mathrm{x}_{0}=\left[\mathrm{H}^{+}\right]^{*} \\
& x_{3 n+1}=F\left(x_{3 n}\right) \\
& x_{3 n+2}=F\left(x_{3 n+1}\right) \\
& x_{3}(n+1)=\frac{x_{3 n+1}^{2}-x_{3 n} x_{3 n+2}}{2 x_{3 n+1}-x_{3 n}-x_{3 n+2}} \\
& {\left[\mathrm{H}^{+}\right]=\lim _{\mathrm{n} \rightarrow \infty} \mathrm{x}_{3 \mathrm{n}} \text {. }}
\end{aligned}
$$

It can be shown that this sequence is convergent if the expression.

$$
\frac{F^{\prime}(\mathrm{x}) F^{\prime \prime}(\mathrm{x})}{F^{\prime}(\mathrm{x})-1}
$$

is bounded in a region around the point $x=\left[\mathrm{H}^{+}\right]^{*}$ and if this point lies close enough to the correct value of $\left[\mathrm{H}^{+}\right]$: This condition, however, is always fulfilled for our particular function $F(x)$ if the time increments are s.mall enough.

It is also possible with this option to calculate equilibria of the. form

$$
\begin{aligned}
& \mathrm{OH}^{-}+\mathrm{B}_{\mathrm{i}} \mathrm{OH}^{+} \rightleftharpoons \mathrm{B}_{\mathrm{i}}(\mathrm{OH})_{2}, \quad\left(\mathrm{~K}_{\mathrm{ii}}^{\prime}\right) ; \\
& \mathrm{OH}^{-}+\mathrm{B}_{\mathrm{i}}^{++} \rightleftharpoons \mathrm{B}_{\mathrm{i}} \mathrm{OH}^{+}, \quad\left(\mathrm{K}_{2 \mathrm{i}}^{\prime}\right)
\end{aligned}
$$


In this case, the dissociation constants must be defined as

$$
\mathrm{K}_{1 \mathrm{i}}^{\prime} \doteq \frac{\left[\mathrm{OH}^{-}\right]\left[\mathrm{B}_{\mathrm{i}} \mathrm{OH}^{+}\right]}{\left[\mathrm{B}_{\mathrm{i}}(\mathrm{OH})_{2}\right]} ; \mathrm{K}_{2 \mathrm{i}}^{\prime}=\frac{\left[\mathrm{OH}^{-}\right]\left[\mathrm{B}_{\mathrm{i}}^{++}\right]}{\left[\mathrm{B}_{\mathrm{i}} \mathrm{OH}^{+}\right]}
$$

However, it is not possible to treat both types of equilibrium in the same : run.

\subsubsection{Steady-state Routine}

The second option is independent of the nature of the particular. species, and therefore more versatile and more convenient to use. It is, however, less economical in regard to computer time. The calculations are performed in a subroutine called EQUIL3, by means of the following procedure.

For a species $A_{j}^{\prime}$ which has reached a quasisteady state, we have the equation.

$$
\frac{d c_{j}}{d t}=g_{j}+\sum_{i} \alpha_{j i} c_{i 1}^{\prime} c_{i 2}^{\prime}=0
$$

This is a quadratic equation of the form

$$
A_{0}+A_{1} c_{j}+A_{2} c_{j}^{2}=0 \text {. }
$$

For the coefficients, one can obtain the expressions

$$
\begin{aligned}
& A_{0}=g_{j}+\sum_{i} \delta_{j}^{\prime 1 i} \delta_{j}^{\prime 2 i} c_{i 1}^{\prime} c_{i 2}^{\prime} \alpha_{j i} ; \\
& A_{1}=\sum_{i}\left(\delta_{j}^{1 i} \delta_{j}^{\prime 2 i} c_{i 2}^{\prime}+\delta_{j}^{11} \delta_{j}^{2 i} c_{i 1}^{\prime}\right) \alpha_{j i} ; \\
& A_{2}=\sum_{i} \delta_{j}^{1 i} \delta_{j}^{2 i} \alpha_{j i},
\end{aligned}
$$

where $\delta ! i k=1-\delta_{j}^{i k}$. The other denotations are the same as in Sect. 3.1. From the three coefficients the computer calculates

$$
c_{j}= \begin{cases}-A_{0} / A_{1} & \text { for } A_{2}=0 \\ \left(-A_{1}-\sqrt{A_{1}^{2}-4 A_{0} A_{2}}\right) / 2 A_{2} & \text { for } A_{2} \neq 0 .\end{cases}
$$


If more than one species is to be processed by the Steady-state Routine, the program goes through the described procedure for each species separately, regarding the concentrations of the other species as constant. The entire sequence is repeated in an iteration procedure until all values remain sufficiently constant. No attempt was made to establish convergence conditions for this sequence, but as yet no case of divergence has been encountered.

\section{OTHER OPTIONS OF THE PROGRAM}

\subsection{Skipping of Species}

It occurs very often that the concentrations of one or more species drop to negligible values after some time, so that they have no more influence on the kinetic system. In this and other cases it is possible to "skip" this species starting in a desired time interval, i.e., to take it out of the calculation routine and assign to it a fixed concentration (for example 0 ) which will then be used for all further calculations. The skipping routine is also useful for species with large and practically constant concentrations, such as $\mathrm{H}_{2} \mathrm{O}$ or dummy species with the concentration 1 (see Sect: 6.1.1).

The skipping option must be used furthermore for the species processed by the Ionic Equilibrium Routine as far as their concentrations are in a steady state (normally $\mathrm{H}^{+}$and $\mathrm{OH}^{-}$), and all the species treated by the Steady-state Routine (see the example in Sect. 6.4.3). The concentrations. of skipped species are in this case periodically adjusted by the equilibrium routines, but not effected by the main program.

A skipping instruction cannot be canceled:' It stays in effect through all succeeding time intervals.

\subsection{Skipping of Reactions}

It is also possible to "skip" reactions in a way similar to the skipping of species, if, for example, a reaction becomes insignificant after some (model) time. A skipped reaction will be disregarded in the calculation process. This skipping instruction also cannot be revoked.

Even if all the species involved in a particular reaction have been skipped, it is still advisable to skip the reaction too in order to reduce computing time. The results will of course not be affected by the latter instruction. 
4.3 "Freezing" of Time Increments.

In some cases, for example if a chemical solution is irradiated continuously at a constant dose rate, the automatic time-increment routine may cause the time increments to decrease after some maximum has been reached. This decrease is often unnecessary from the standpoint. of accuracy, since all concentrations are close to a steady state or are in-... creasing at a linear rate. In such cases it is possible to "freeze" the time increments in the last time interval. They can then only increase but not decrease:

\section{INPUT AND OUTPUT}

\subsection{General Requirements and Format of Input}

Figure 2 shows the format of all the input data described in this paragraph: The required-data are

(a) A number (up to 4 digits) assigned to the particular run and a punch control digit:: If this digit is different from zero, the results will be punched on cards (additionally to the printed output) for use with a plotting. program.

(b) A list of chemical reactions with their second-order rate constants. in liter mole $e^{-1} \mathrm{sec}^{-1}$. In case of reactions of the type $A+A \rightarrow B+\ldots$, which contribute to the differential equation for the species A a term $-2 k A^{2}$, the value $k$, not $2 k$, must be entered. There must be two species on the left side of each equation, and there may be up to four species on . the right side. Minus signs on the right side will be arithmetically treated as such; a minus sign on the left side will be treated as plus: No numerical factors are allowed; e.g., instead of " $2 \mathrm{H}_{2} \mathrm{O}$ " one has to enter " $\mathrm{H}_{2} \mathrm{O}+\mathrm{H}_{2} \mathrm{O}$." Up to 30 reactions are allowed. The end of the list must be indicated by a blank card. A card with zero as rate constant will be treated as blank.

(c). A list of species with G-values in particles per $100 \mathrm{eV}$, rates of spontaneous formation in moles liter $\mathrm{r}^{-1} \mathrm{sec}^{-1}$, equivalent conductances in mho $\mathrm{cm}^{2}$ gram-equivalent ${ }^{-1}$, and molar absorptivities in liter $\mathrm{cm}^{-1}$ ! mole ${ }^{-1}$. As species, any Holerith word with up to 5 characters, but with no leading blanks, may be used. Plus and minus signs in this Holerith word, except such in the place of the first character, are counted by a special subroutine ("SCAN") for determining the charge of the species.

In columns 7 and 8 a value for the charge other than zero may be entered, which will then override the value determined by the subroutine.

All of the species on the left side of the reaction equations must be included in the list, those on the right side only if their concentrations are to be calculated. The species may be numbered in columns 1-5 
for. convenience; the se numbers will be ignored. The maximum number of species is 27 . The end of the list must be indicated by a blank card.

(d) A list of time intervals with dose rates and instructions concerning the application of the equilibrium and skipping routines. Characters in columns $1-5$ are again ignored so that these columns can be used for numbering. The values in columns 11-20 denote the end of each time interval (in sec); columns 21-30 contain the dose rates in eV liter $\mathrm{sec}^{-1}$. In columns 31-35 and 36-40, respectively, the Holerith names of two species to be skipped may be listed. For each of the se species, a concentration value must be assigned and punched in columns 41-50 or 51-60, respectively, except if subroutine EQUIL 3 is called in this time interval. Up to 5 reactions to be skipped may be listed in columns 61-63, 64-66, 67-69, 70-72, and 73-75, respectively, by the numbers of their position in the list of reactions.

Column 80 is used for instructions regarding the use of the equilibrium routines with the following code.

0 or blank: equilibrium routines not used

1: EQUIL2 (ionic equilibrium) is used

2: EQUIL3 (steady state) is used

3: both routinès are used

The instruction to call either or both of the routines cannot be revoked in succeeding time intervals.

If the digit 2 or 3 is punched in column 80 , any values in columns 41 through 60 are ignored. Species marked for skipping on such a card are in this case automatically treated by the Steady-state Subroutine (EQUIL3), and they will be assigned the value which they had at the end of the preceding time interval. Likewise, reactions which are marked for skipping on such cards will only be skipped in the main routine, but not in subroutine EQUIL3, whereas reactions marked for skipping on cards with a 1,0 , or blank in column 80 will be disregarded in the entire process of calculation.

(e) A single card which lists the accuracy factor q (see Sect. 3:3), the number $n_{p}$ of cycles (time increments) between consecutive printouts of results, the minimum print interval $\Delta t_{p}$ 'min (which is the minimum time distance in sec between two printouts), the minimum time increment $\tau_{\min }$ in sec, the maximum time increment $\tau_{\max }$ in such time intervals where no equilibrium routine is used, the maximum time increment $\tau_{\max , e q}$ in such time intervals where at least one of the routines is used, and a "time increment freeze index" $i_{t}$. If the latter is different from zero, the time increments will be "frozen" during the last time interval. 
If the said card is blank, the following values will be as.sumed by the computer:

$$
\begin{aligned}
\mathrm{q} & =0.05 ; \\
\mathrm{n}_{\mathrm{p}} & =250 ; \\
\Delta \mathrm{t}_{\mathrm{p}, \min } & =0 ; \\
\tau_{\min } & =\mathrm{T}_{\mathrm{nt1}} / 10^{6} ; \\
\tau_{\max } & =\mathrm{T}_{\mathrm{nt} 1} / 200 ; \\
\tau_{\max , \mathrm{eq}} & =\mathrm{T}_{\mathrm{nt}} / 10000 ; \\
\mathrm{i}_{\mathrm{t}} & =0 .
\end{aligned}
$$

Here $T_{n t}$ is the end of the last time interval and $T_{n t l}$ the end of the last time interval for which no equilibrium routine is used. Any values other than zero punched into this card will override the corresponding values given above. Of the two values $\Delta t_{p}$, min and $n_{p}$, the one resulting in a. larger print interval overrides the other one.

(f) A list of equilibrium equations, followed by a blank card. If the Ionic Equilibrium Routine is not used, this list, but not the blank card, is omitted. The equilibrium equations must be entered in the sequence shown in Sect. $3: 4: 2$, i.e., the second stage of dis sociation must succeed the first one. If this sequence is reversed, an error message will be printed out. If there is no second dissociation stage, the corresponding equation must be omitted. No blank cards are allowed between equations. Figure 2 shows the required form of the equations. Dissociation constants must be given as defined in Sect. 3.4.2. There may be up to 10 pairs of equilibrium equations ( $\left.n_{e q} \leq 10\right)$.

Any number of runs [ complete sets of data as described under (a) through (f)] may be stacked in one computing sequence.

\subsection{Output}

Figure 3 shows an example of the printed output normally obtained. This figure is essentially self-explanatory.* The meaning of the abbreviations can be found in Sect. 7. The concentrations are printed out in groups of 6. Conductivity change, absorbance change, and time increment are printed in the same table after the concentrations. The maximum number of printed lines per group is 250. If this number is reached, the run will be terminated.

*In some cases, rows of asterisks a re printed instead of the value 0 . This does not affect the calculations. 
Fig. 3. Mathematical Model for the Pulse Radiolysis of Pure Degassed Water

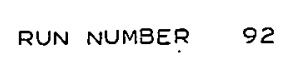
INITIAL CONDUCTIVITY $\equiv 5: 491-008 \mathrm{MHO} / \mathrm{CM}$
INITIAL AESOREANCE

no time dose rate species MOLES/L MOLES/L REATPPED

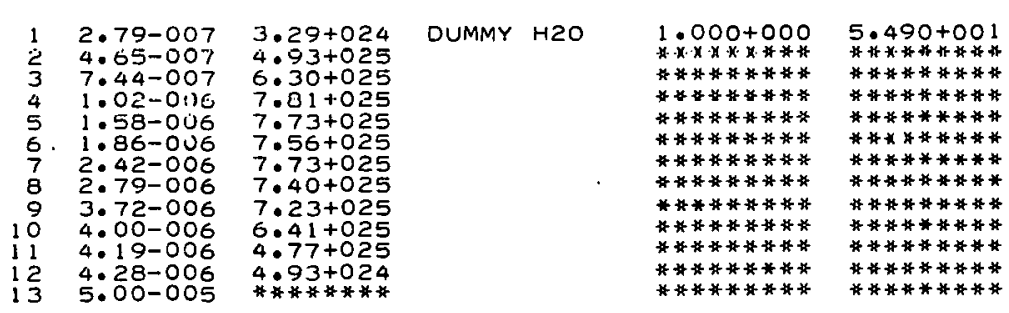

ACCURACY FACTOR 1. OOOOOI
ALUES PRINTEO OUT EVERY D.
M

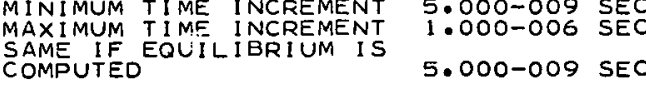
$\begin{array}{ccccccc}\text { TIME } & \text { HL } & \text { HO2 } & \text { OL- } & \text { OL } & \text { HZO } & \text { DUMMY } \\ \text { SECONOS } & \text { MOLES/L } & \text { MOLES/L } & \text { MOLES/L } & \text { MOLES/L } & \text { MOLES/L } & \text { MOLES/L }\end{array}$
SECONOS MOLESA MOLES/L MJLES/L MOLES/L MOLES/L MOLES/L MHOICM ACM

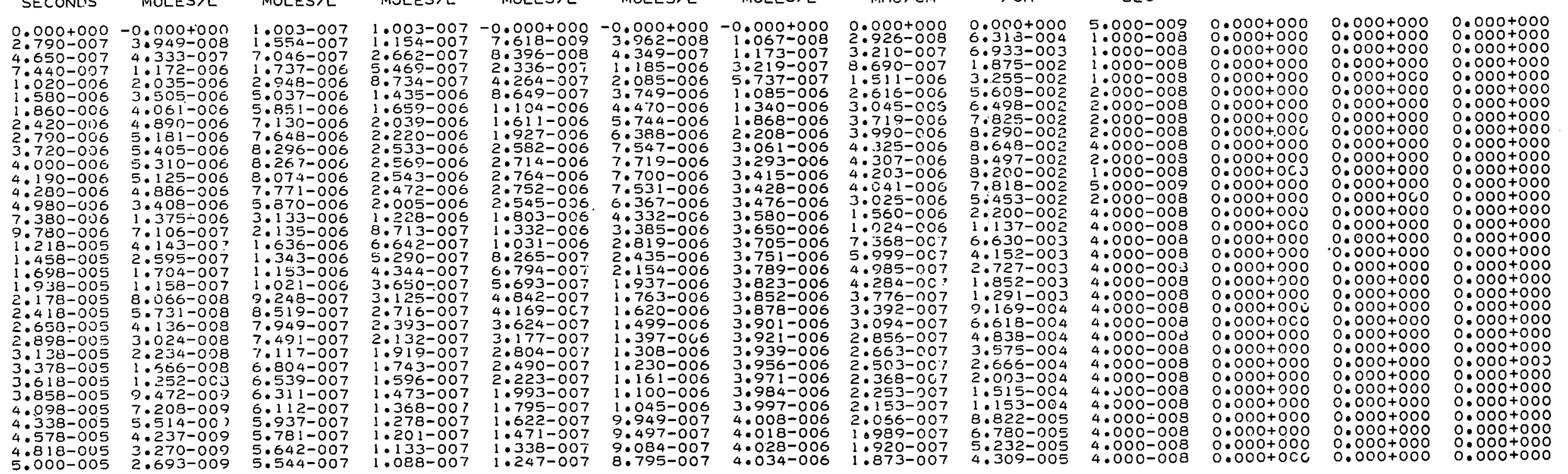

$0.000+000-0.000+000-0.000+000-0.000+000 \quad 10000-006 \quad 5.490+001 \quad 1: 000+000$

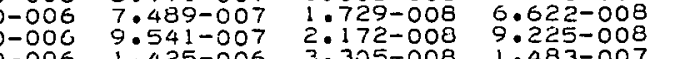

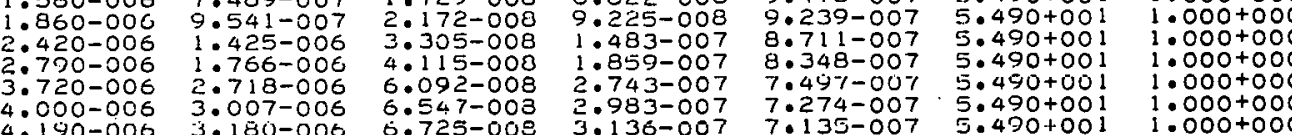

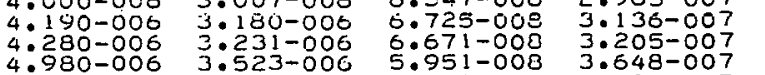

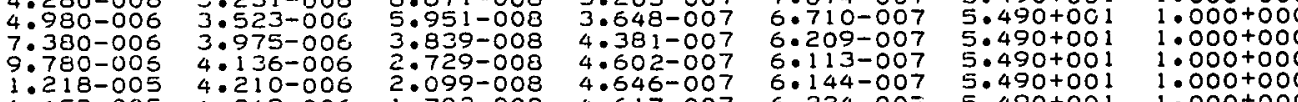

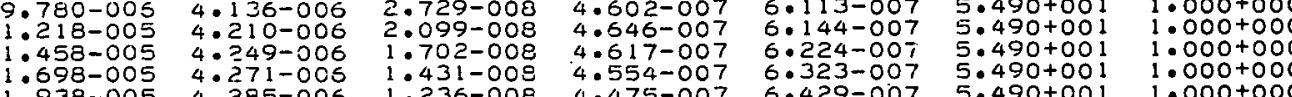

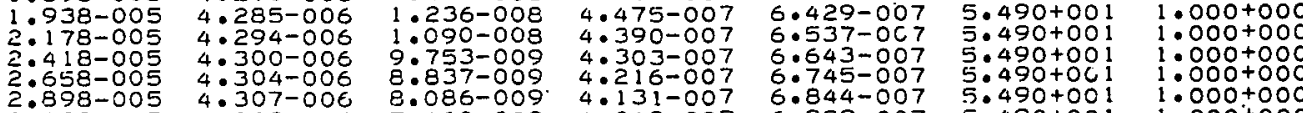

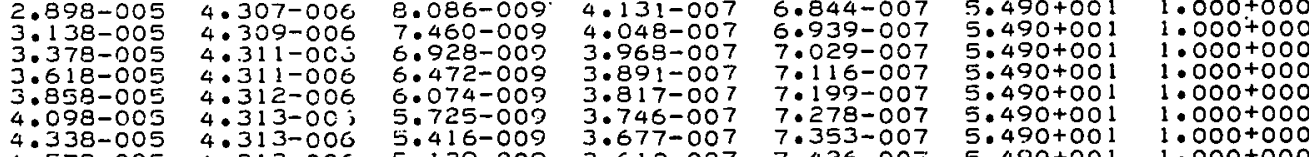

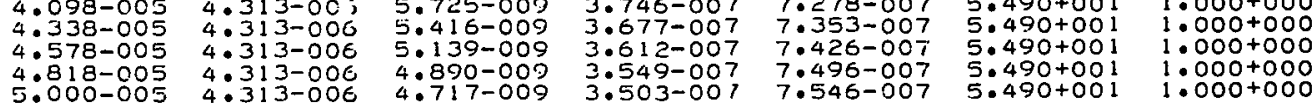


Fig. 4. Calculation of the $\beta$ Emission of Radon and Its Decay Products
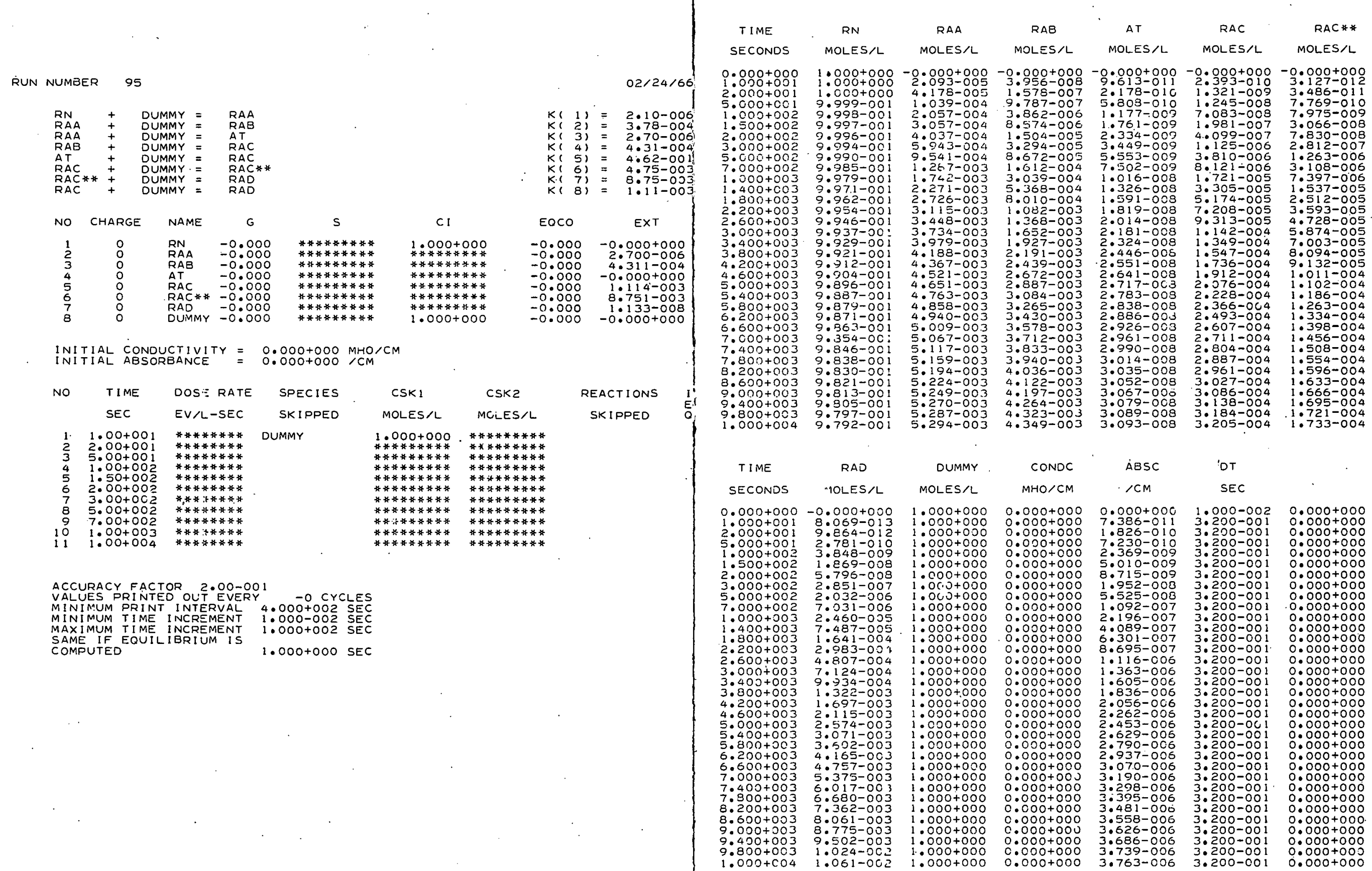
The interval between successive printouts is determined by the values of $n_{p}$ or $\Delta t_{p}, m i n$. Furthermore, printouts are always given at $t=0$ and $t=T_{n}\left(n=1, \ldots, n_{t}\right)$, i.e., for the time values punched in columns $11-20$ of the cards in group d (Sect. 5.1 and Fig. 2).

If the punch index [ see Sect. $5.1,(a)$ ] is not zero, the results, but not the data, are also punched on cards for use with a plotting program.* Figure 4 shows an example of the punched output. The line 95* 134 1.000+004 means: Run No. 95, Group No. 1, 34 lines of results per group, maximum time $\left(\mathrm{T}_{\mathrm{nt}}\right) 10^{4} \mathrm{sec}$. In the lines marked (MAX) and (MIN), the minimum and maximum value of each column is given.** The last card of each group is a blank card with a minus sign in the 80 th column.

*A plotting program for use with an IBM-1620 (40k) computer, provided with an IBM-1627 plotter, may be obtained from the author.

**If the two values have the same sign, the value closer to 0 will be replaced by 0 . 


\section{SUGGESTIONS FOR THE USE OF 'THE PROGR AM}

\subsection{Application of the Program in Some Special Cases}

\subsubsection{First-order Reactions}

A first-order reaction of the type $A \rightarrow B+\cdot \ldots$ with $\lambda$ as the firstorder rate' constant (decay constant) can be entered in the form

$$
A+D U M M Y=B+\ldots(\lambda)
$$

"DUMMY" is a dummy species to which is as signed the concentration 1 . In order to keep this concentration constant, the species DUMMY must be "skipped" (with CSK = 1).

\subsubsection{Third- and Fourth-order, Pseudo Second-order Reactions}

A reaction of the type $A+B+C+D \rightarrow E+F$ whose rate is determined by the concentrations of $A$ and $B$ only, can be entered in the form

$$
A+B=E+F-C-D
$$

with $\mathrm{k}$ as second-order rate constant.*

\section{1 .3 Labeling of Species}

For some studies, for example if the contribution of one particular reaction to the yield of a certain product is to be determined, species can be "labeled" in a way analogous to the radioactive tracer method. Thus, in the reaction scheme

*An example for such a reaction is

$$
\mathrm{O}_{2}^{-}+\mathrm{O}_{2}^{-}+2 \mathrm{H}^{+} \rightarrow \mathrm{H}_{2} \mathrm{O}_{2}+\mathrm{O}_{2} \text {. }
$$

This can be regarded as the net reaction of the sequence

$$
\begin{array}{lc}
\mathrm{O}_{2}^{-}+\mathrm{O}_{2}^{-} \rightarrow \mathrm{O}_{2}^{-} & \left(\mathrm{k}_{1}\right) \\
\mathrm{O}_{2}^{-}+\mathrm{H}^{+} \rightarrow \mathrm{HO}_{2}^{-} & \left(\mathrm{k}_{2}\right) \\
\mathrm{HO}_{2}^{-}+\mathrm{H}^{+} \rightarrow \mathrm{H}_{2} \mathrm{O}_{2} & \left(\mathrm{k}_{3}\right)
\end{array}
$$

in which the first reaction is rate-determing. 

(1) $A+B=E \quad\left(k_{1}\right)$
(2) $C+D=E \cdot\left(k_{2}\right)$
(3) $E+E=F \quad\left(k_{3}\right)$

the relative contributions of the three different ways: in which the product $F$ is formed, can be studied by writing the reaction system as
$A+B=E^{*} \quad\left(k_{1}\right)$
$C \cdot+D=E \quad\left(k_{2}\right)$
$E+E=F \quad\left(k_{3}\right)$
$E+E^{*}=F^{*} \quad\left(k_{3}\right)$
$E^{*}+E^{*}=F^{* *} \quad\left(k_{3}\right)$

It may be pointed out that all labeled and unlabeled species. must appear in the list of species.

\subsubsection{Photochemical Reactions}

Under certain. restrictions, photochemical reactions can be studied with the program in a way similar to reactions induced by ionizing radiations. One possibility is to replace G-values by quantum yields, and to enter the radiation intensity with the dimension "(quanta per 100 liters) per second." This application of the program is possible if the absorption of the effective wavelength by the irradiated substance does not change appreciably during the reaction.

\subsubsection{Calculation of Other Linear Combinations of Concentrations}

Instead of the optical absorbance, other linear combinations of concentrations,

$$
L=\sum x_{j} c_{j}
$$

can be calculated by entering the factors $x_{j}$ in the EXT column. $L$ is then obtained as $L_{0}+\triangle \mathrm{L}$, where $\mathrm{L}_{0}$ is printed under INITIAL ABSOR BANCE and $\triangle \mathrm{L}$ appears in the ABSC column. With certain restrictions, the EQCO and CONDC columns may also be used for this purpose by entering the values $\left(1000 \mathbf{x}_{j}\right)$ under EQCO and assigning to all the species:involved the charge $Q_{j}=+1$. In this case, subroutine EQUIL2 cannot be used. Furthermore, 
the printout of the values $\left(1000 \mathrm{x}_{\mathrm{j}}\right)$, but not that of the results, may be incorrect due to the output format specification ( $F$ 10.3) for the EQCO column.

\subsubsection{Reactions. with .More Than.Four Products.}

Reactions of the type

$$
\mathrm{A}+\mathrm{B} \rightarrow \mathrm{C}+\mathrm{D}+\mathrm{E}+\mathrm{F}+\mathrm{G}+\mathrm{H} \cdot(\mathrm{k})
$$

can be entered as a.combination of two reactions as follows:

$$
\begin{aligned}
& A+B=C+D+E+F \\
& A+B=G+H+A+B \quad(k)
\end{aligned}
$$

The concentrations. of $A$ and $B$ are not affected by the second reaction:

\subsection{Special.Error Messages and Countermeasures}

A number of error messages are provided by the program and.its subroutinges:

(1) : ERROR IN EQUILIBRIUM EQUATIONS, RUN ABANDONED" .

This message is printed:if (a) the first species in all equilibrium equations is not the same or (b) if the equilibrium equation for the second stage of dissociation: precedes the equation.for the first stage. The program then proceeds to the next run.

(2) "DIVERGENCE IN EQUIL2, EQUILIBRIUM NOT COMPUTED, RUN ABANDONED"

This imessage appears if the iteration procedure for computing the equilibrium of ionic species has not sufficiently converged after 20 .steps. This can only occur if the main program produces erroneous concentration values, e.g., if the time increments are too great. After printing this mès.sage, the program proceeds to the next run.

Possible remedies: Check data, especially time increments, for the main program. Check equilibrium equations for errors.

\section{(3) "DIVERGENCE IN EQUIL3, RUN AB̈ANDONED"}

This message is printed if the iteration process in the Steadystate Routine has not sufficiently converged after 20 steps. The program then proceeds to the next run. 
Pósible remedies: Check data for errors. Check time increments; reduce them if feasible. Change sequence of the species treated in this subroutine in such a way that they are arranged in the order of decreasing rate of change.. (The subroutine treats the species in the order in which they are listed in the list of species.)

\section{(4) "LESS THAN 20 SEC LEFT, SEQUENCE TERMINATED"}

If only $20 \mathrm{sec}$ of the computing. time assigned to the computing sequence are left, all the values calculated up to that point are printed out. The entire sequence is then terminated.

Possible remedies: Increase accuracy factor as far as possible. Use freezing option where applicable. Simplify reaction-system. Use equilibrium routines as far as possible.

\section{(5) "PRINT LIMIT REACHED, RỤN TERMINATED"}

If the limit of 250 lines of results per group is reached, these results are printed out. The program then proceeds to the next run.

Possible remedies: Increase minimum print interval $\left(\Delta \mathrm{t}_{\mathrm{p}, \mathrm{min}}\right)$ or number of cycles between printouts $\left(n_{p}\right)$.

\subsection{First Trial Run}

If one wants to study a new reaction system, it is often difficult to make reliable quantitative estimates about the behavior of the system, which are necessary to determine parameters such as the maximum (model) time range, minimum time increments, etc., and the necessity and feasibility of using the equilibrium options. In. such cases. it has proven useful to start with a trial run without the equilibrium and freezing options; with a maximum time range $\left(T_{n t}\right)$ that is large compared to the estimated reaction time, and with a parameter card e that is blank except for the minimum time increment $\tau_{\text {min. }}$. As $\tau_{\text {min }}$ one may choose $1 / 1000$ of the estimated lifetime of the (supposedly) fastest reacting species. For the other parameters to be entered on card $e$, the computer will then use the values listed in Sect. 5.1, (e). The computer time limit should be set at $10 \mathrm{~min}$.

It is very likely that in this trial run one of the error messages listed in Sect. 6.2 will appear, but even so the results obtained will permit suitable adjustments of the data. Completely erroneous concentration values such as $-4.718 \times 10^{172}$ often indicate that the time increments are too large. This, however, is very unlikely with an accuracy factor of 0.05 .

\subsection{Examples of Computer Runs}

In the following paragraphs, three computations carried out with program WR 16 are presented for illustrative purposes. The data are shown 
in the format in which they were printed out by the computer. They were entered in the format shown in Fig. 2. The data used in the third example are suitable as test data since they require all the main features of the program and subroutines.

\subsubsection{Example 1: Pulse Radiolysis of Pure Degassed Water}

In this example, the behavior of pure degassed water during and after irradiation with a $4-\mu$ sec electron pulse from a $15-\mathrm{MeV}$ linear accelerator was studied. All important chemical reactions presently known or supposed to take place between the radiation-produced intermediates and products have been taken into account. ${ }^{2}$ As rate constants, yields, etc., experimental values were used in most cases; some values were estimated. An initial $\mathrm{O}_{2}$ concentration of $10^{-6} \mathrm{M}$ was as sumed, since "degassed" water without special treatment still contains approximately this amount of oxygen. The dose-rate values assumed were those measured in an actual experiment; the nonrectangular pulse shape was taken into account by approximating it by a stair function. The equilibrium routines were not used, so that the value for $\triangle t_{\max }$ eq ("SAME IF EQUILIBRIUM IS COMPUTED") has no significance. The complete computer printout is shown: in Fig. 3. The required computer time for this run was $43 \mathrm{sec}$.

\subsubsection{Example 2: Decay Products of Radon}

This computer run illustrated the possibility of studying first-order reactions. The columns: EXT and ABSC were used to calculate the total $\beta$ emission (in particles/sec per radon atom). In the branch $R a C-R a C-R a D$, the very short-lived $\left(1.5 \times 10^{-5} \mathrm{sec}\right)$ intermediate $\mathrm{RaC}$ ' was omitted.

As an accuracy factor, the relatively large value of $0: 2$ was chosen, since mathematical considerations indicate that for first-order reactions larger time increments may be used for obtaining a given accuracy than for second-order reactions.

The printout for this run is shown in Fig. 4. The results are presented in the form in which they were punched out for plotting purposes. The required computer time was $4 \mathrm{~min} 16 \mathrm{sec}$. This time could have been considerably shortened by applying the Steady-state Routine EQUIL3 for the species At, the lifetime of which ( $1.5 \mathrm{sec})$ is very short compared to the overall time range.

6.4.3 Example 3: Removal of Traces of Oxygen from Hydrogen-saturated Water by Preirradiation with a $\mathrm{Co}^{60}$ Source

is

For this study essentially the same reaction scheme was assumed as in example 1. The printout of the data and results is shown in Fig. 5. Reactions 1, 4, 10,12, 21, and 22 of example 1 (Run No. 92) were omitted as supposedly unimportant: Two new reactions (18 and 19. in Rún No. 93), 
Fig. 5. (Contd.)

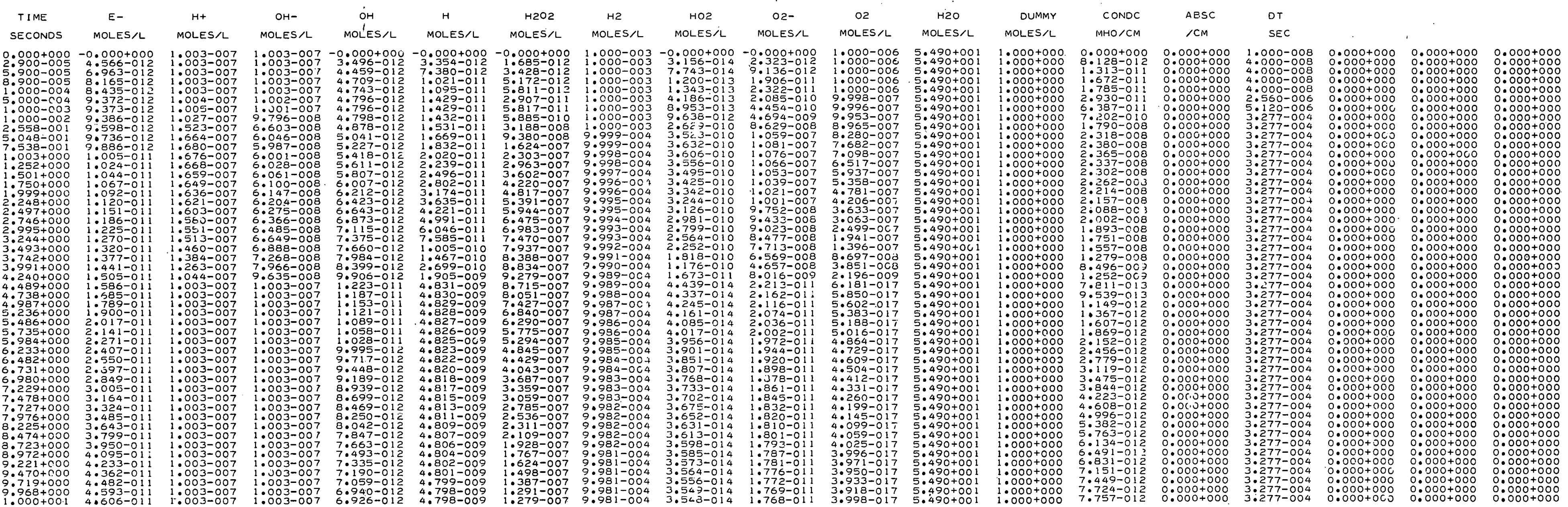


Fig. 5. Mathematical Model for the Deoxygenation of Water by Irradiation RUN NUMBER 93 $03 / 11 / 66$
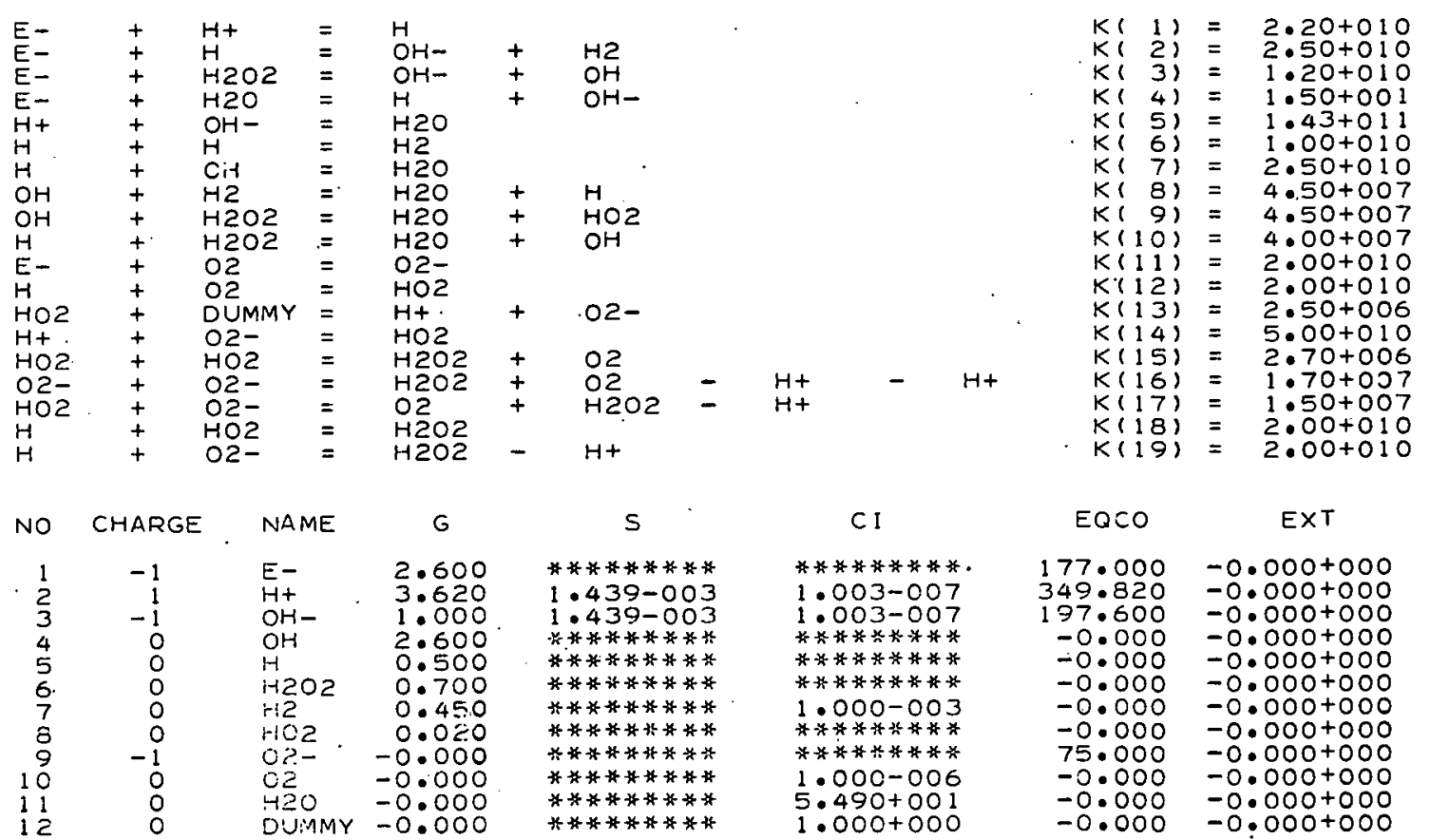

EQCO EXT

NITIAL CONDUCTIVITY $=5.491-008 \mathrm{MHO} / \mathrm{CM}$

\begin{tabular}{|c|c|c|c|c|c|}
\hline TIME & $\begin{array}{l}\text { DOSE RATE } \\
\text { EV/L-SECC }\end{array}$ & $\begin{array}{l}\text { SPECIES } \\
\text { SKIPPED }\end{array}$ & $\begin{array}{c}\text { CSK1 } \\
\text { MOLES/L }\end{array}$ & $\begin{array}{l}\text { CSK2 } \\
\text { MOLES/L }\end{array}$ & $\begin{array}{l}\text { REACTIONS } \\
\text { SKIPPED }\end{array}$ \\
\hline $\begin{array}{l}1: 00-004 \\
5: 00-004 \\
1: 00-003 \\
1: 00-002 \\
1000+001\end{array}$ & $\begin{array}{l}5.00+018 \\
5: 00+018 \\
5: 00+018 \\
5: 00+018 \\
5: 00+018\end{array}$ & $\begin{array}{ll}\text { Dummy H2O } \\
\mathrm{H} \\
\mathrm{H} \\
\mathrm{H} & \mathrm{OH}- \\
\mathrm{E}-\mathrm{H}\end{array}$ & 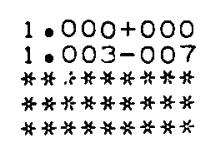 & $\begin{array}{l}5: 40 \\
1: 00 \\
\forall * * * 1 \\
* * * * 1\end{array}$ & $\begin{array}{r}7 \\
1 \\
-1 \\
-0 \\
-0\end{array}$ \\
\hline
\end{tabular}

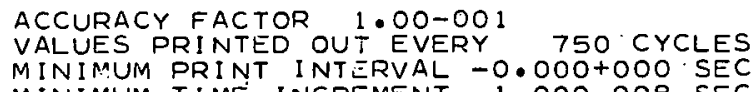
MINIMUM TIME INCEMENT $1: 00000008$ SEC
MAXIUM TIME INCEMENT $50000-007$ SEC
SAMEUI EOUILIBRUM IS

SAME IF EQUILIBRIUM IS $5.000-004 \mathrm{SEC}$
COMPUTED

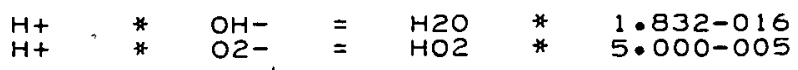


which might have some influence on the rate of removal of oxygen, were added. An initial concentration of $10^{-3} \mathrm{M}$ was assumed for $\mathrm{H}_{2}$. The supposed effect of such an $\mathrm{H}_{2}$ concentration is the conversion of most of the oxidizing $\mathrm{OH}$ radicals into reducing $\mathrm{H}$ atoms via reaction 8. Although there is a net formation of oxygen in $\mathrm{H}_{2}$-free water, the addition of hydrogen effects a net decay by causing a considerable decrease in the rate of formation of oxygen via the reactions $9,13,15,16$, and 17 , so that, as this calculation and also experiments ${ }^{3}$ show, traces of oxygen can be practically completely removed within a few seconds of irradiation.

For the first $10^{-4}$ sec none of the equilibrium routines were used, in order to give the charged species time to reach a quasisteady state. After that, the ionic equilibria as determined by the two equilibrium equations printed at the end of the data were computed. For this purpose, the fastreacting species $\mathrm{H}^{+}$and $\mathrm{OH}^{-}$had to be skipped. At the same time it was possible and desirable to skip reactions 5,13 , and 14 since these affected only the species adjusted by the equilibrium routine. The species $\mathrm{H}, \mathrm{E}-$, and $\mathrm{OH}$ have reached a quasisteady state after about $5 \times 10^{-4} \mathrm{sec}$. Therefore, the Steady-state Subroutine EQUIL3 could have been. introduced at that time for adjusting these species, which implied skipping reactions 1, 2, 4, and 7 . As already mentioned in. Sect. 5.l, the latter instruction causes these reactions to be disregarded by the main program, but not by EQUIL3.

The reason why E- was skipped after $10^{-3}$ rather than $5 \times 10^{-4}$ sec is simply that skipping instructions for only 2 species can be given in each time interval; further, it was also desired to force printouts at $10^{-3}$ and $10^{-2} \mathrm{sec}$. The value 0.1 was chosen as an accuracy factor because this value had previously yielded results of good accuracy in most cases. Trial runs had shown that a minimum time increment of $10^{-8} \mathrm{sec}$ was sufficiently small; this value is smaller by a factor of 4 than the one later chosen by the computer. The space reserved for T $\max$ on data card e was left blank; the printed value is therefore that determined by the computer. For $\tau_{\text {max, eq }}$ a value smaller than usual was chosen since in this particular case a considerable increase in accuracy could be accomplished at the expense of a relatively small amount of additional computer time (more than half of the total computer time was needed for the first $10^{-3} \mathrm{sec}$ of model time).

\section{FORTRAN NOTATION}

Table II includes the names of all variable and constant numbers and arrays used in the main program and/or subroutines except for those whose definition is evident from the source deck listings. Arrays are given without their dimensions. 
TABLE II. FORTRAN Notation in WRI6 and Sủbroutines

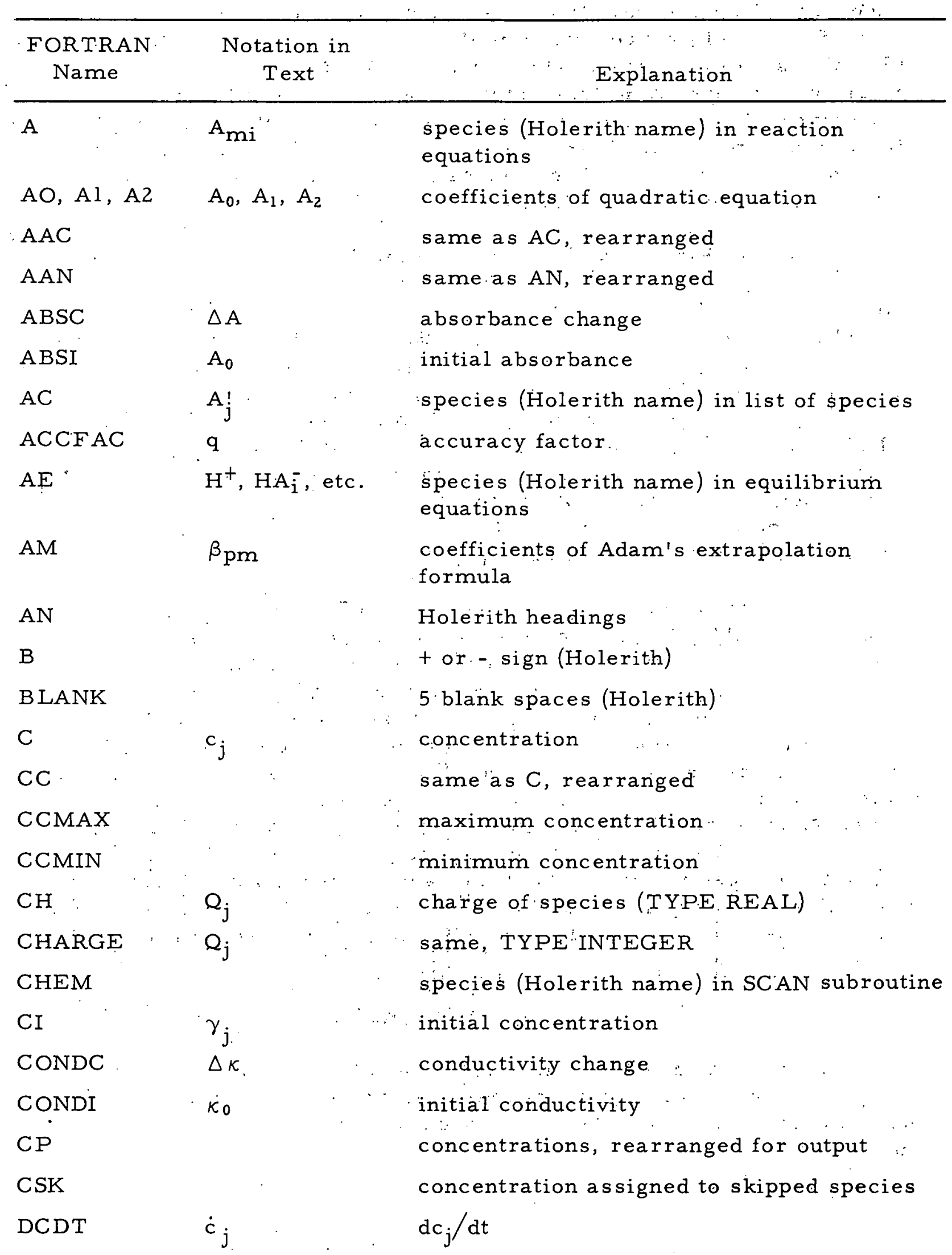


TABLE II (Contd.)

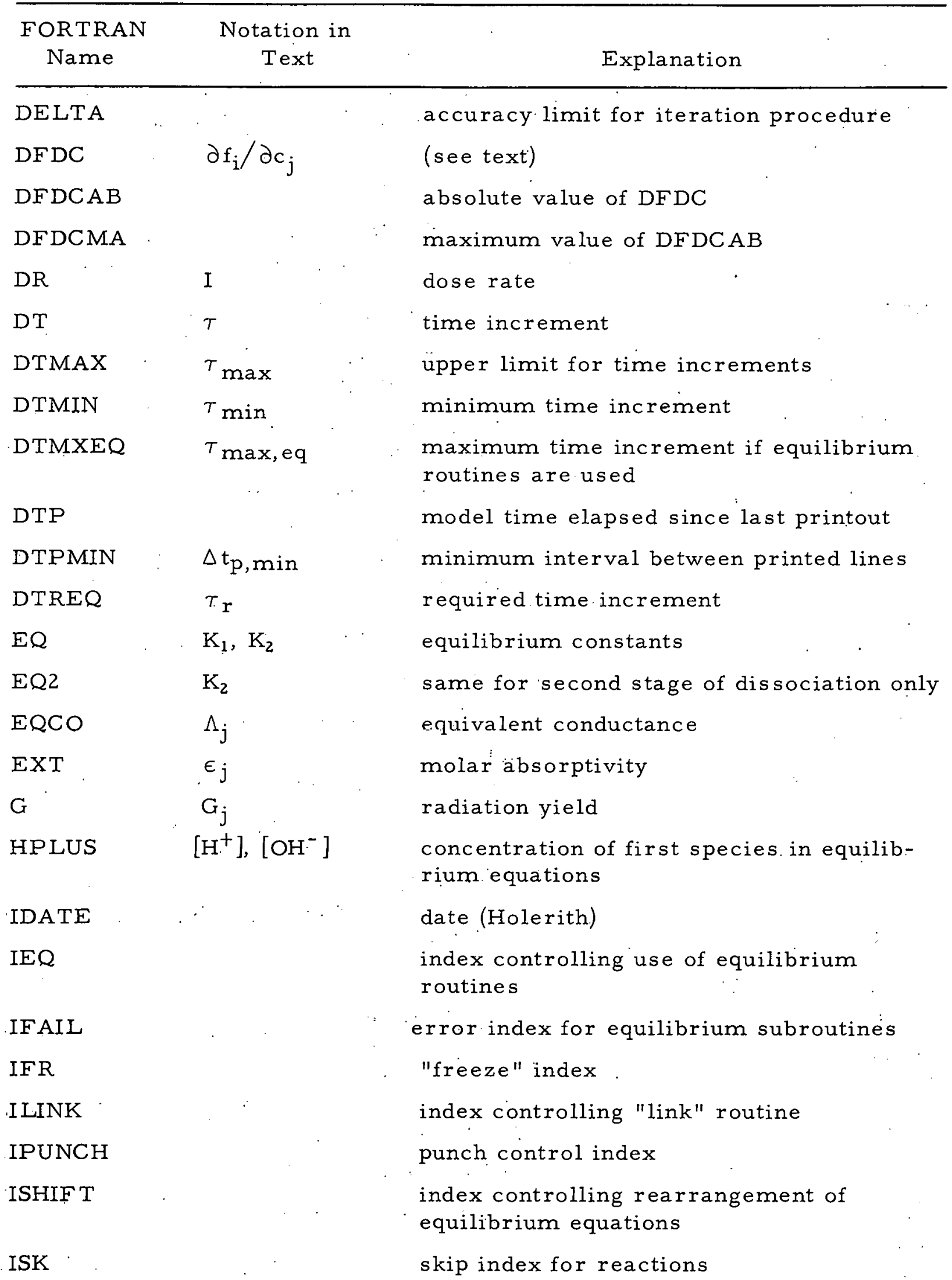


TABLE'II (Contd.)

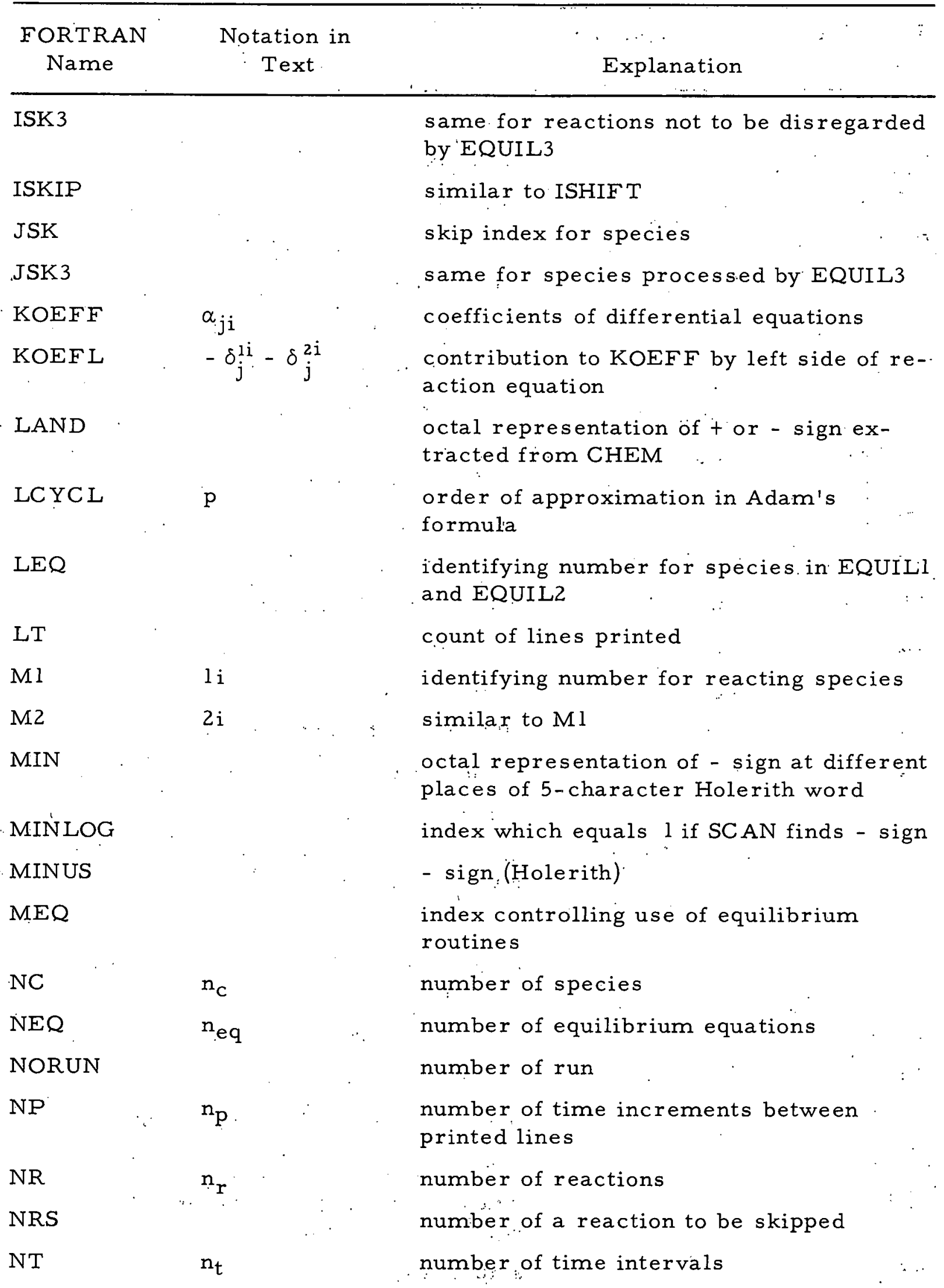


TABLE III (Contd.)

\begin{tabular}{|c|c|c|}
\hline $\begin{array}{l}\text { FORTRAN } \\
\text { Name }\end{array}$ & $\begin{array}{c}\text { Notation in } \\
\text { Text }\end{array}$ & Explanation \\
\hline NTl & $\mathrm{n}_{\mathrm{t} 1}$ & $\begin{array}{l}\text { number of time intervals in which equilib- } \\
\text { rium routines a re not used }\end{array}$ \\
\hline $\mathrm{OCT}$ & & octal numbers $007700 \ldots, 00007700 \ldots$ etc. \\
\hline $\mathrm{P}$ & $\mathrm{p}$ & $\begin{array}{l}\text { order of approximation (maximum value } \\
\text { of NCYCL) }\end{array}$ \\
\hline PLU & & $\begin{array}{l}\text { octal representation of }+ \text { sign at different } \\
\text { places of } 5 \text {-character Holerith word }\end{array}$ \\
\hline PLULOG & & index which equals 1 if SCAN finds + sign \\
\hline RF & $g_{j}$ & rate of formation (without decay) \\
\hline RK & $\mathrm{k}_{\mathrm{i}}$ & rate constant \\
\hline $\mathrm{S}$ & $s_{j}$ & rate of spontaneous formation \\
\hline SLOPE & $\Delta c_{j} / \tau$ & $\begin{array}{l}\text { slope of line connecting successive points } \\
\text { of } c_{j}(t)\end{array}$ \\
\hline SPSK & & species skipped \\
\hline $\mathrm{T}$ & $\mathrm{T}_{\mathrm{n}}$ & end of each time interval \\
\hline TIME & $\mathrm{t}$ & model time \\
\hline TLFT & & real computing time left (in $\mathrm{msec}$ ) \\
\hline TOTAL & $\mathrm{C}_{\mathrm{Ti}}$ & total amount of $i$-th acid (or base) \\
\hline $\mathrm{TT}$ & & model time (stored for output) \\
\hline XMAX & & same as CCMAX (rearranged) \\
\hline XMIN & & same as CCMIN (rearranged) \\
\hline
\end{tabular}

\section{LISTING OF FORTRAN SOURCE DECKS}

In the sücceeding pages of this section, the FORTRAN source decks of the main program and all required subroutines are listed, with the exception of the ANL library subroutine TIMEF ${ }^{3}$ which makes available to the FORTRAN program the date (IDATE) and the computer time in milliseconds remaining in the current computing sequence (TIMELEFT).

The following subroutines are required for the main program WR 16 :

SCAN (Determines the charge of a species from the number of minus or plus signs in its Holerith notation) 
STORE (stores model time and concentration values selected for output. Calculates and stores the change in conductivity $(\Delta K)$ and optical absorbance $(\triangle A)$ by means of the expressions

$$
\begin{gathered}
\Delta \kappa=-\kappa_{0}+\left(\sum_{j} Q_{j} \Lambda_{j} c_{j}\right) / 1000 \\
\Delta A=-A_{0}+\sum_{j} \epsilon_{j} c_{j},
\end{gathered}
$$

(where $\kappa_{0}$ and $A_{0}$ are the initial values for conductivity and $a b-$ sorbance, $\Lambda_{j}$ is the equivalent conductance, $\epsilon_{j}$ is the molar: absorptivity)

EQUILl. (Reads and prints equïlibrium equations. Checks for second stage of dissociation and renumbers equations)

EQUIL2 (Computes equilibrium of ionic species)

EQUIL3 (Computes steady-state concentrations of fast-reacting species)

\section{TIMEF (See above)}

PROGRAM WR1G

PROGRAM WR 16
WATER RADIOLYSIS, WITH EQUILIBRIUM. FOR COC $360^{\circ}$. K. SCHMIDT. . WR16

TYPE INTEGER AC, BL-ANK, AAC IA, S, AN, AAN, SPSK, AE, CHARGE, P

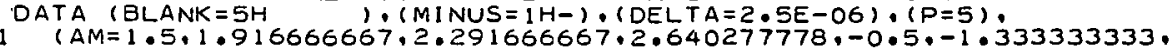

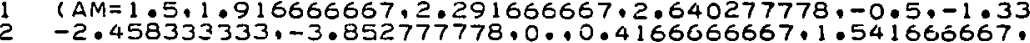

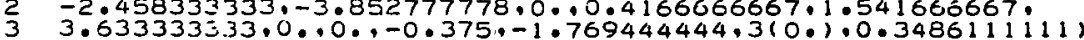

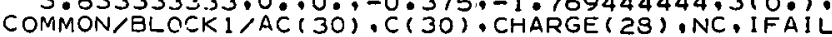

COMMON/BLOCK2/AE (3.11). LEQ $(4,11)$, EQ(1) 1). NEQ.EO2 $(11)$ COMMON/BLOCK 3 /DELTA

COMMON/BLOCK 4/TIME.TT (250), CC $(30,250)$, CONDI . ABSI . DT .EQCO(28), 1 EXT (28), LT , NPR,DTP,NC1,NC2,NC3

COMMON/BLOCKS /RF ( 27$)$, RK $(3 i)$, MI $1(30)$. M2 (30) . KOEFL $(27.30)$,

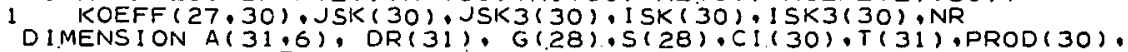

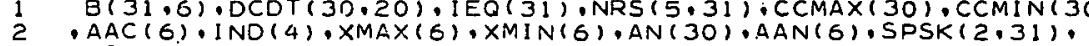

3 CSK $(2,31), A M(4,5)$

1 READ 200 , NORUN. I PUNCH

I=IDATEI (O.)

IF (EOF.60) 600.2

C READ, COUNT AND FRINT CHEMICAL REACTIONS

3 DO 5 I $=1,31$

READ 201 , (A $(I, K), K=1,3),(B(I, K)$, $,(I, K), K=4,6), R K(I)$

IF (RK (I) $) 5,6,5$

5 PRINT $301,(A, I, K), K=1,3),(B(1, K), A(I, K), K=4,6), I, R K(1)$

$c$

READ, COUNT AND PRINT SPECIES.ETC.

PRINT 302

DO $10 \quad J=1,28$

READ 203,CHARGE (J), AC $(J), G(J), S(J), C I(J)$, EOCO $(J), E X T(J)$ IF (CHARGE $(J) \cdot E Q \cdot O)$ CALL SCAN $(C H A R G E(J), A C(J))$

10 PRIAT 303.J.CHARGE (J), AC (J),G(J),S(J),CI (J),EOCO (J),EXT (J)

$11 N C=J-1$

DEFINE. SOME VALUES

$N C 1=N C+1 \$ N C 2=N C+2$ \& $N C 3=N C+3$

DO $12 J=N C 1 \cdot 30$

c

COMPUTE AND PRINT INITIAL CONOUCTIVITY AND OPTICAL DENSITY CONDI $=0$. \$ ABSI $=0$. DO $100 M=1, N C$

CONOI=CONDI+CI (M) *EOCO $(M)$ \#ABSF (FLOATF $(C H A . R G E(M))) * 0.001$

100 AES I = ABS I +CI $(M) \# E X T(M)$

C PRINT 400 . CONDI.ABSI I TOST RATE VALUES

PRINT 304

DO $15 K=1.31$

READ $205, \dot{T}(K), D R(K), \operatorname{SPSK}(1, K), \operatorname{SPSK}(2, K), \operatorname{CSK}(1, K), \operatorname{CSK}(2, K)$ 

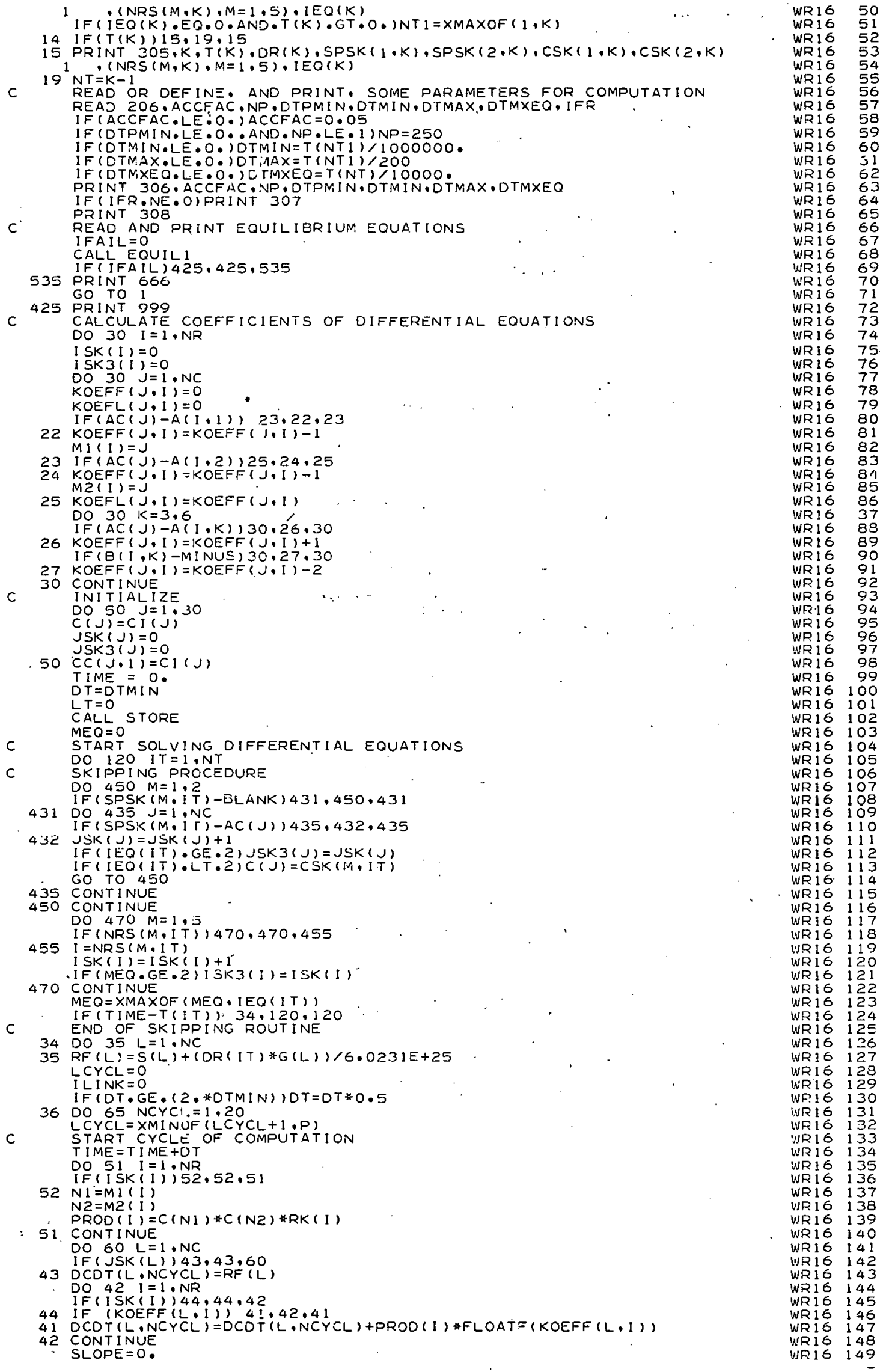
55 STLCYCL

$\mathrm{GO}$ TC 50

56 DO $57 \mathrm{~K}=1, \mathrm{LCYCL}$

57 INDK=NCYCL+2O+1-K-2O*( (NCYCL +2O-K) $/ 20)^{\circ}$

57 SLOPE = SLOPE+AM(LCYCL-1,K)\#DCDT (L. INOK)

GO TO 59

C \#LINK\# ROUTINE FOR COMPUTING SLOPE

58 IDIF $=-1$ (

DO $158 K=1, P$

I STEP =1

IF $((K+I L I N K) \cdot G T \cdot(P+1))$ I STEP $=2$

I $D I F=$ I DIF + ISTEP

I NDK $=N C Y C L+20-10 I F-20 *($ (NCYCL $+20-10 I F-1) / 20)$

158 SLOPE $S L O P E+A M(P-1, K)$ *DCDT (L.INDK)

C CALCULATE AND STORE NEW CONCENTRATIONS

59. IF (TIME. T T (IT) I 159.258

$258 C(L)=C(L)+S L O P E *(D T+T(I T)-T I M E)$

GO TO 60

$\begin{array}{rl}159 & C(L)=C(L)+D T * S L O P E \\ 60 & C O N T I N U E\end{array}$

259 IF (T IME :GE.T (I T ) ) $259 \cdot 160$

TCYCI $=0$ (T)

LCYCL $=0$

160 IL INK $=$ XMAXOF $(0$. IL INK-1)

NPR $=N P R+1$ \$ DTP $=D T P+D T$

IF (NPR.GE.NP. AND.DTP.GE.DTPMIN.AND.MEQ.EQ.0)62.65

GS CONTINUE

$C$

CHECK TIME LIMIT

TLF T = T I MELEFT $(O \cdot)$ IF (TLFT.LE. 20000 , ) GO TO 130

IF ( (MEQ.EQ.1.OR.MEQ.EQ.3). AND.NEQ.GT.0) CALL EQUILZ IF (MEQ.GE.2) CALL EQUIL3

IF (MEQNE 0175.273

75 .IF(IFAIL) 174.174 .575

575 PRINT 666

GO TO 130

174 LCYCL $=0$

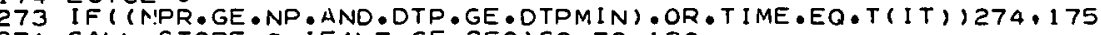

274 CALL STORE $\$$ IF (LT.GE.25O)GO TO 130 IF ( TIME.EQ.T (IT) ) 120,175

c REDE TERMINE TIME INCREMENTS

175 DFDCMA $=0$.

DO $360 L=1$.NC

IF (JSK (L) $\bullet G E \bullet 1)$ GO TO 360

DFDC $=0$.

DO $350 \quad 1=1$. NR

IF $(I S K(I), G E$
$M 1 I$

IF (MI I EO. L) DFDC=DFOC+FLOATF (KOEFF (L.I ) )\#RK(I)\#C(M2I)

350 CONT

DFDCAB=ABSF (DFDC)

360 CONT INUE

DTRE Q = ACCFAC/DFDCMA

DTMX $=D T M A X$

ITMX =DTMAX

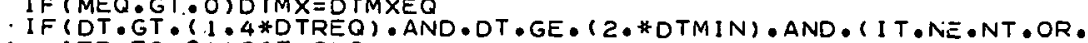
IFR.EQ.0;; 365,370

365.

LCYCL $=0$

370 IF (DT.LT. $(0.7 * D T R E Q)$. AND.DT -LE. $(0.5 * D T M X)) 375 \cdot 36$

$375 D T=2 *$ DT

I $L I N K=P-1$

120 GONTO 36

DIFFERENT I AL EQUATIONS SOLVED.

130 DO $121 M=1,30$

$121 \operatorname{CCMIN}(M)=0$. $\$ \operatorname{CCMAX}(M)=0$

DO $125 \mathrm{M}=1, \mathrm{NC} 3$

DO 125 LL $=1 . L T$

IF (CC (M.LL) : GT.CCMAX(M)) CCMAX (M) =CC (M,LL)

125 CONTINUE

, L T CCMIN(M) ; CCMIN $(M)=C C(M \cdot L L$ ?

DEF I NE COLUMN HEADINGS

220 O $220 \mathrm{~J}=1$. NC

AN $225 \quad J=N C 1,30$

225 AN $(J)=7 \mathrm{H}$

$A C(N C 1)=5 H C O N D C$

$A C(N C 2)=5 H A B S C$

$A C(N C 3)=5 H C T$

$A N\left(N C_{1}\right)=7 H$ MHO $/ C M$

$A N(N C 2)=7 H \quad / C M$

C AN(NC3)=7H SEC

ARRANGE RESULTS FOR OUTPUT.

I GROUP $=(\mathrm{NC} 3+5) / 6$

DO $1501 \mathrm{TG}=1$ I IGROUP

IF (I PUNCH•GT.O) PUINCH 315,NORUN, IG.LT,T(NT)

DO $140 \mathrm{~L}=1.6$

$I G L=(I G-1) * 6+L$
WR16 150

WRIG 151

WR16 152

WRI 15 154

WR $16 \quad 154$

WR16 155

WR $16 \quad 156$

WR 16158

WRIG I59

WR16 160

WR16 161

WR16.162

WR $16 \quad 163$

WR16 164

WR 16 i 65

WR16 166

WR16 167

WRIG 168

WRIS 169

WR16 170

WRIG 171

WR 103

WR $16 \quad 173$

WR16 174

WRI 165

WR16 176

WR $16 \quad 177$

WR $16 \quad 178$

WR $16 \quad 179$

WR $16 \quad 180$

WR16 181

WR16 182

WRIG IB3

WR $16 \quad 184$

WR $16 \quad 185$

WR 16 IB6

WR 16187

WRIG 187

WR

WRIG 189

WR16 190

WR16 131

WR16 192

WR16 193

WR IS 194

WR16 195

WR 16196

WR16 197

WRI 198

WR $16 \quad 199$

WR $16 \quad 200$

WR 16201

WR 16202

WRIS 203

WRIS 204

WR 16 204

WRI 206

WRIG 206

WR16 207

WRIG 209

WR16 209

WR $16 \quad 210$

WR16 212

WR I 5 213

WR $16 \quad 214$

WRIG 215

WR $16 \quad 216$

WR $16 \quad 217$

WRIG 218

WR 16219

WR.16 220

WR $16 \quad 221$

$\begin{array}{ll}\text { WR } 16 & 222\end{array}$

WR $16 \quad 223$

WR 16 224

WR16. 225

WR $16 \quad 225$

WR16 226

WR16 227

WR16 228

WR1G 229

WR $16 \quad 230$

WR $16 \quad 231$

WR $16 \quad 232$

WR $16 \quad 233$

WR $16 \quad 234$

WR $16 \quad 235$

WR $16 \quad 236$

WR $16 \quad 237$

WR 16 238

WR 16239

WR16 240

WR16 241

WRI 242

WR16 243

WR 6 244

WR $16 \quad 244$

WRIG 245

WR $16 \quad 246$

WRIO 247

$\begin{array}{ll}\text { WR16 } & 248 \\ \text { WR16 } & 249\end{array}$ 
$A A C(L)=A C(I G L)$

$A A N(L)=A N(I G L)$

$X M A X(L)=C C M A X($ I GL)

$140 \times M I N(L)=C C M I N(I G L)$

PRINT $310,($ AAC $(L), L=1,6),($ AAN $(L), L=1,6)$

IF (IPUNCH) $142,142,141$

141 PUNCH $310,($ AAC $(L), L=1,6),($ AAN $(L), L=1,6)$

PUNCH $311,(X M A X(L) \cdot L=1,6)$

142 DO 144 LL $=1, L T$

DO $145 \mathrm{~L}=1.6$

I $G L=$ (I G-1) $* S+L$

c

PUNCH AND $/ O R$ PRINT RESULTS

IF ( I PUNCH.GT.O) PUNCH 313, TT (LL), (CP(L),L=1,6)

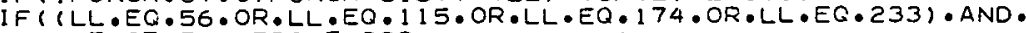

1 (LT.GT.57) IPRINT 999

144 PRINT 313 , TT(LL), (CP(L), L $=1,6)$

PRINT 999

IF (IPUNCH.GT.O) PUNCH 998

150 CONTINUE

I F (TLFT:LE.20000 ) PRINT 667

IF (LT.GE.250)PR INT 668

600 CALL EXIT

200 FORMAT $(1 \times, I 4,15)$

201 FORMAT $(3(5 X, A 5), 3: 1 \times, A 1,3 X, A 5), 5 X, E 15,2)$

203 FORMAT $(6 \times, 12,2 \times$.AS.E $10.3,3 E 15,3, E 10.3)$

2O5 FORMAT ( $5 \times, E 15.3, E 10.3,2 A 5,2 E 10.3 .513 .4 \times$. I 1 )

206 FORMAT (E10.3.15.4E10.3.15)

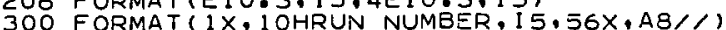

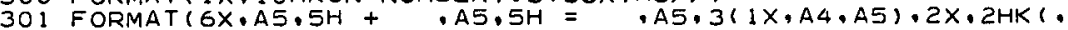

301

02 FORMAT $(/ / 6 \times 2$ 2HNO $2 \times 26 \mathrm{HCHAR}$

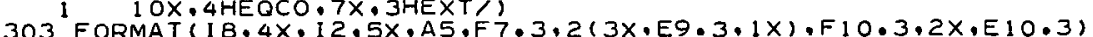

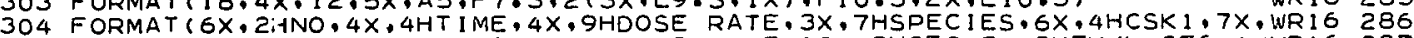

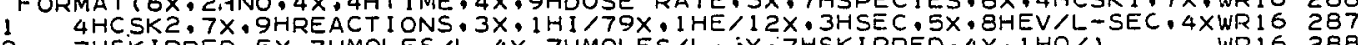

2 . THSKIPPED, $5 \times$, 7HMOLES/L, 4X,7HMOLES/L, $X, 7 H S K I P P E D, 4 X, 1 H Q / 1$ WR 16 288

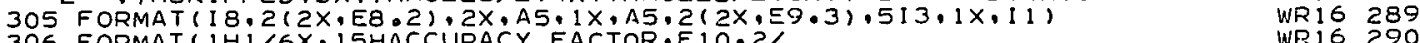

306 FORMATIIHI/6X.15HACCURACY FACTOR,E10.2' WR 16 290

1 6X.24HVALUES PRINTED OUT EVERY I 6 :7H CYCLES/

2 SX.23HMINIMUM PRINT INTERVAL E IO:3.4H SEC/

$36 \times .23 H M I N I M U M$ TI IME INCREMENT. E $10.3,4 \mathrm{H}$ SECI

4 6X.23HMAXIMUM TIME INCREMENT. $510.3,4 \mathrm{H}$ SEC' $15 \times, 510.3,4 \mathrm{H}$ SEC,

307 FORMAT (6X. * TIME INCREMENTS FROZEN IN LAST TIME INTERVAL*)

308 FORMAT ( $(1)$ (

310 FORMAT $(6 \times, 4 H T I M E, 3 \times, 6(5 \times, A 5,1 X) / 1$

$15 \times, 7$ HSECONDS, $6(4 \times, A 7), 3)$

311 FORMAT $(6 \times, 5 H(M A X) \cdot 2 X \cdot 6 E 11 \cdot 3)$

312 FORMAT $(6 \times \cdot 5 H(M I N)$

313 FORMAT $(2 \times, 7 E 11.3)$

315 FORMAT (I $4.1 H^{*}, \mathrm{I} 1,1 \mathrm{H}^{*}, 13, \mathrm{E} 10.3 /$ )

1 FORMAT $(/ 6 \times$ * INITI I AL CONDUCTIVI
$6 \times$ * INIT I AL ABSORBANCE

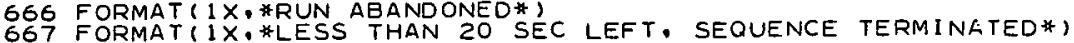

668 FORMAT ( $1 \times$ * *PRINT LIMIT REACHED, RUN TERMINATED*)

998 FORMAT $(79 \times, 1 \mathrm{H}-)$

ऽ9 FORMAT ( 1 H 1 (

END PROGRAM WRIG

SUBROUT INE SCAN (CHARGE. CHEM)

TYPE INTEGER OCT,PLU, CHEM, CHARGE

TYPE INTEGER OCT PPLO, CHEM

TYPE LOG I CAL MINL JG, PLULOG $(4)$, LAND ( 4 ), MINLOG (4), PLULOG (4)

DIMEN!SION

DHARCE $=0$

DO 10 I $=3.6$

OCT $(7-I)=63 * 64 * * I$

$10 \operatorname{PLU}(7-1)=\operatorname{MIN}(7-1) / 2$

$D O, 50 \quad I=1.4$

LAND (I ) =CHEM.AND.OCT ( I )

MINLOG $(1)=M I N(I)-L A N D(I)$

PLULOG $(1)=P L U(I)-L A N D(I)$

I $F(M I N L O G(I) \cdot E Q \bullet O) \quad C H A R G E=C H A R G E-1$

IF ( PLULO

RETURN

END SUBROUTINE SCAN

SUBROUTINE STORE

C CALCULATE CONDUCTIVITY AND ABSORBANCE. STORE SET OF OUTPUT VALUES TYLE INTEGER CHARGE

COMMON

COMMON/BLOCK4 TTME, TT (250), CC(30.250), CONDI, ABSI, DT,EOCO $(28)$,

1 HXT (2B), LT, NPR,DTP. NC1, NC2, NCJ

$E X T(2 B) \cdot L T$ NPR
CONDC $=-C O N D I$ I ABSC $=-A B S I$

$L T=L T+1$

DO $20 \mathrm{~L}=1$. NC

$C C(L, L T)=C(L)$

$T T(L T)=T I M E$

CONDC $=$ CONDC $+C(L) * E Q C O(L) * A B S F(F L O A T F(C H A R G E(L))) * 0.001$

20 ABSC $=A B S C+C(L) * E \times T(L)$

$C C(N C 1, L T)=C O N D C$

$C C(N C 2, L T)=A B S C$

$C C(N C 3, L T)=D T$

IF (NC3-30) $25,40,40$

$25 \mathrm{NC4}=\mathrm{NC} 3+1$

DO $3 C \quad L=N C 4 \cdot 30$

$30 \quad C C(L \cdot L T)=0$.

RETURN

END SUBROUTINE STORE

WR 16 291

WR 16293

WR $16 \quad 294$

WR 16 235

WR 16296

WP $16 \quad 297$

WR $16 \quad 298$

WR 16299

WR $16 \quad 300$

WR 16301

WR $16 \quad 302$

WR16 303

WR 16305

WR 16306

WR16 306

WR 16308

WR 16309

WR $16 \quad 310$

WR $16 \quad 311$

SCANOOOO

SCANOOJZ

SCANOOO 3

SCANOOO 4

SCANOOOS

SCANOOOG

SCANOOOB

SCANOOOB

SCANOOOO

SCANOO 11

SCANOO 12

SCANOO 13

SCANOO 14

SCANOOIS

SCANOO 16

STORE

STORE

STORE

STORE

STORE

STORE

STOR

STORE

STOR

STORE 10

STORE 11

STORE 12

$\begin{array}{ll}\text { STORE } & 13 \\ \text { STORE } & 14\end{array}$

STORE 15

STORE 16

STORE I8

STORE 19

STORE 20

STORE.
STORE 22 
C RUBROUTINE EQUILI

TYPE INTEGER AC,AE.BLANK. CHARGE

A

COMMON/BLOCK2/AE (3,11), LEO $(4,11)$, EO $(11), N E G, E O 2(11)$

DIMENSION ISHIFT $(: 0)$, ISKIP $(10)$

DATA (BLANK $=5 \mathrm{H}$

DEAD $510=1 \dot{1} O(M, K), M=1,3), E O(K)$

IF (AE (I,K) -BLANK 1510.511 .510

510 PRINT $311,(A E(M, K), M=1,3), E Q(K)$

c

NEQ=K-1

DO $520 \mathrm{~K}=1 . \mathrm{NEO}$

$\begin{array}{lll}D O & 520 & K=1, N E \\ D O & 520 & M=1,3\end{array}$

DO $515 L=1 \cdot N C$

IF (AC (L) $-A C(M \cdot K)) 515,512,515$

512 LEQ $(M+K)=L$

515 CONTINUE

IF (L-NC) $520,520.526$

c

CONTINUE

ERROR CHECK

DO $525 K=1 . N E O$

I $F(A E(1, K)-A E(1,1)) 526.525 .526$

DISSOCIATION STAGE. RENUMBER

I SKIP $(1)=0$

DO $630 \mathrm{~K}=1$ =

DO $630 K=1$ N NEO

I SHIFT $(K+1)=I S H I F T(K)$

LEO $(4, K)=N C+1$

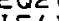

(K) $630,605,630$

605 IF (LEQ $(2, K)-L E Q(3, K+1)) 630,610.630$

610 IF (LEQ (3.K)-LEQ $(2, K+1) .1615 .526 .615$
615 EQ2(K) $=E Q(K+1)$

$\operatorname{LEQ}(4, K)=\operatorname{LEQ}(2, K+1)$

I SHIFT $(K+1)=I S H I F T(K)+$

630 CONTINUE

DO $650 K=1 \cdot . N E Q$

IF(ISKIP(K))650,635,650

$635 E O(K-I S H I F T(K))=E \cdot)(K)$

$E Q 2(K-I S H I F T(K))=E O 2(K)$

DO $640 M=1,4 F T(K))=L E Q(M, K)$

640 LEOIM.KK
650 CONTINUE

$N E Q=N E Q-I S H I F T(N E Q)$

GO TO 530

526 PRINT 77

IFAIL $=1$

530 RETURN

211 FORMAT $(3(5 \times, A 5) \cdot 5 \times \cdot E 10.3)$

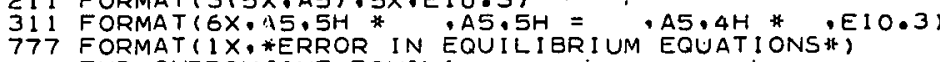

END SUGROU TINE EOUILI

SUBROUTINE EQUILZ

C COMPUTE EQUILIBRIUM OF IONIC SPECIES

TYPE INTEGER AC, AE, CHARGE

COMMCN/BLOCK I /AC (30), C (30), CHARGE : 28 ) , NC, IFAIL

COMMON/BLOCK 2/AE (3.11), LEQ $(4,11)$, SQ (11), NEQ, EQ2 (1)

COMMON/BLOCK $3 / D E L T A$

DIMENSION HPLUS (3), TOTAL (1O)

DIMENSION HPL SCH I FOATF (CHARGE (LEQ 1 ),

HPLUS $(1)=C$ (LEO1)

DO $540 \mathrm{~K}=1$. NEQ

LEO2K $=L E Q(2, K)$

$L E Q 3 K=L E Q(3, K)$

EOAK=LEO ( $4, K)$

540 TOTAL $(K)=C($ LEQ2K $)+C(L E Q 3 K)+C(L E Q 4 K)$

DO 560 NSTEP $=1,20$

DO $555 \quad 1=2 \cdot 3$

DO $545 K=1$, NEQ

LEQ2K $=L E Q(2, K)$

LEQ $3 K=L E Q(3, K)$

C (LEO3K) $=$ TOTAL $(K) /(1,+E O(K) / H P L U S(1-1)+E Q(K)$ *EO2 (K)/HPLUS $(I-1) *$ *2) EQUL

C(LEQZK)=EQ(K) *C CLEQ3K) $Y H P L U S(1-1), \quad$ EOU2

HPLUS (I) =HPLUS $(1-1)$

DO 551 L $=1$, NC

DO 551 L $=1$ PNC $550,551,550$

550 HPLUS( I) = HPLUS (I) -CH\#FLOATF (CHARGE (L) ) *C(L)

551 CONTINUE

CONTINUE

IF (CHECK-DELTA*0.1) 1553.553 .555

$553 C(L E Q 1)=(H P I-U S(1)+H P L U S(1-1)) 2$.

GO TO 562

555 C(LEQ1)=HPLUS(I)

HPLUSO $=$ HPLUS $(1)$ ( $)(2) * 2-H P L U S(1) *$ HPLUS $(3)) /(2 \cdot *$ HPLUS $(2)-H P L U S(1)$

1 - HPLUS ( 3$)$ )

$C(L E Q 1)=H P L U S(1)$

CHECK $=$ ABSF $($ (HPLUS $(1)-$ HPLUSO $) /($ HPLUS $(1)+$ HPLUSO $)$

IF(CHECK-DELTA) $562,562,560$

560 CONT INUE

IFAIL $=1$

PRINT 777
GO TC 570

EQU2

EOU2

EOU2

EQU?

EQU2

EQUe

EQU2

EOU2

EQU2

EQU?

EQU2

EQU2

EOU?

EQUe

EOU2 


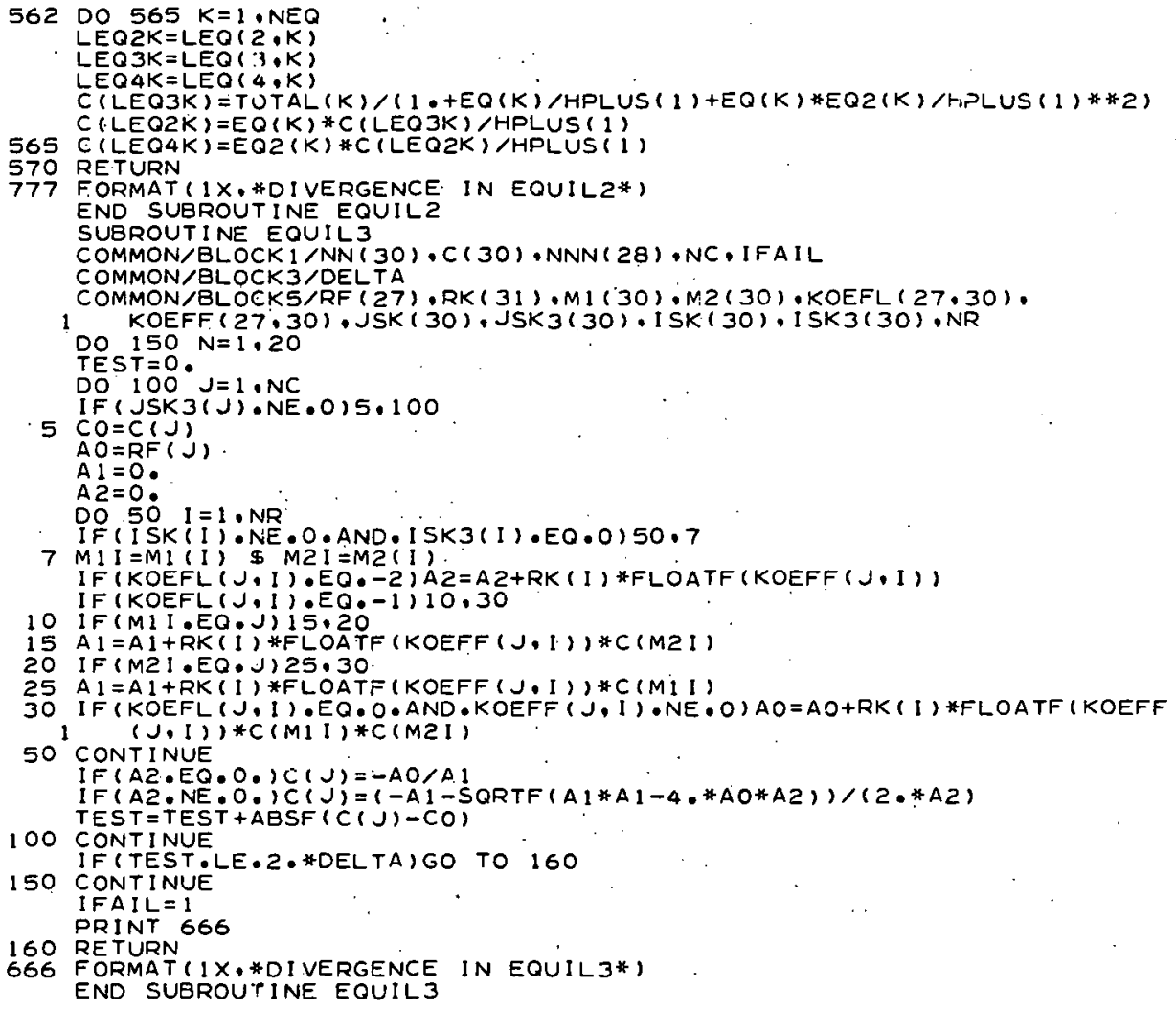




\section{APPENDIX}

Modification of the Program for Use with an IBM-1620 Computer System

Since computers of the type IBM-1620 are more commonly available than the much larger and more expensive CDC-3600, it was attempted to adapt program WR 16 for a computer system of the former type. This was only possible with certain restrictions because of the storage requirements of the program. The adapted program can now be used with an IBM-1620 computer equipped with either a 60-k memory and an IBM-1620 Monitor-I system, or a 40-k memory and an IBM- 1620 Monitor-II system.

In order to reduce storage requirements, the arithmetic portion of the program had to be separated and converted:into a subroutine. Also, Ionic Equilibrium Option had to be eliminated altogether. .

\subsection{Required Programs and Subroutines}

WR17 (Main program, which performs essentially the same operations as program WR16, except that the arithmetic portion has been separated.)

CYCLI7 (Performs most of the arithmetic operations.)

STORE (Essentially the same as the STORE subroutine used with WR 16.)*

EQUIL3 (Essentially the same as the EQUIL3 subroutine used with WR 16.)*

\subsection{Suggested Operating Procedure}

Load main program and subroutines on disk in the usual way described in the IBM reference manual. For execution enter data together with the control cards shown in Fig. 6. These control cards include some storage-saving options:

(1) The Floating-point Arithmetic and the Input-Output subroutines are loaded in core alternatively when they are called (digit 3 on XEQS control card).

\begin{tabular}{|c|c|c|c|c|c|c|c|}
\hline 667890 & $34567890^{2}$ & $7890^{3}$ & 34567590 & 7890 & $\mid 1234567890$ & 1234567890 & $\mid 122456785$ \\
\hline 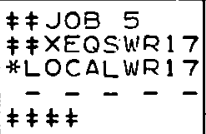 & $\begin{array}{l}04800 \\
\text { CYCL } 17 . \mathrm{EO} \\
--{ }^{2}-\end{array}$ & IL & $T$ DAT & $1-$ & -- & - & - \\
\hline 2.3456789 & 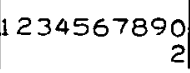 & $\begin{array}{r}90 \\
3\end{array}$ & 5678 & & . & & \\
\hline
\end{tabular}

Fig. 6. Control Cards for Executing Program WRl7

\footnotetext{
* Note that the source deck of this subroutine is somewhat different from the subroutine with the same name used with WRl 6.
} 
(2) The subroutines CYCLI7, STORE, and EQUIL3 a re loaded in core one at a time when required. They occupy the same storage area (LOCAL control card).

Two features of the program controlled by program switches are described in Sect. 9.3.

\subsection{Restrictions and Additional Features of Program WRI7 as Compared to WR16}

(1) Only 25, rather than 30, chemical reactions may be entered.

(2) Only 21, rather than 27, species may be used.

(3) The maximum number of characters in the Holerith notations of the species is 4 , rather than 5 .

(4) The maximum number of time intervals is 20, rather than 30.

(5) Since there is no SCAN subroutine, the charges of the species are not determined. Also, charge values entered with the data are ignored. Instead of the equivalent conductance (EQCO), the atomic conductance ( $\mathrm{ATCO}=\mathrm{EQCO}$ times the valence of the species) must be entered.

(6) There is no Ionic Equilibrium Option. Any digit greater than 0 for IEQ (in column 80 of the d-cards) will put the Steady-state Option (EQUIL3) into effect, i.e., it conveys the same instruction as the digit 2 in program WR16. No equilibrium equations must be entered with the data.

(7) The entire output is punched on cards. The results appear in. the way in which they are punched by WRI 6 with a punch index different from 0 . A punch index will be ignored by WR17. The heading IEQ in WR 6 is replaced by $I E$, the heading CONDC by CNDC.

(8) No date is punched and no time check performed.

(9) Since calculations with an IBM-1620 system require considerably more (approximately 100 times as much) time than those with a CDC-3600, two additional options controlled by program switches on the console have been added which permit the user to follow the computation and terminate it at any desired time. These are the switch settings and their effects:

Program Switch 2 On:

Each time when a set of concentrations, etc., is stored for output, the console typewriter prints the current number of this set, the (model) time, and all concentrations including CNDC, $A B S C$, and DT. [As an example, the printout for $t=2.790 \mathrm{x}$ $10^{-7}$ sec in Run No. 92 (see Sect. 6.4.1) is reproduced in Fig. 7.] 
Program Switches 2 and 3 On:

This has the same effect as if the print limit.were reached. All results stored up to that point are punched out, and the run is terminàted.

$32 \cdot 790 E-07$

$$
\begin{array}{lllllll}
3.949 E-08 & 1.554 E-07 & 1.154 E-07 & 7.618 E-09 & 3.962 E-08 & 1.067 E-08 \\
6.895 E-09 & 2.366 E-10 & 1.996 E-10 & 9.999 E-07 & 5.490 E+01.1 .00 .0 E+00 \\
2.926 E-08 & 6.318 E-04 & 1.000 E-08 & 0.000 E-99 & 0.000 E-99 \cdots 0.000 E-99
\end{array}
$$

Fig. 7. Example of a Typewriter Printout Obtained by Turning on Program Switch 2 .

\subsection{FORTRAN Notation and Listing of Source Decks}

Table III includes those notations used in program WRl 7 and its subroutines that are not used or have a different meaning in program WR 16 and its subroutines.

\begin{tabular}{|c|c|c|}
\hline $\begin{array}{c}\text { FORTRAN } \\
\text { Name }\end{array}$ & $\begin{array}{l}\text { Notation } \\
\text { in Text }\end{array}$ & Explanation \\
\hline A & $\left(A_{\mathrm{ji}}\right)$ & $\begin{array}{l}\text { same as in WR16, except that part of the A matrix: } \\
\text { is used for the quantities forming the } B \text { matrix of } \\
\text { WRI } 6\end{array}$ \\
\hline AAN & . & see NAAl \\
\hline$A N$ & & see NAl \\
\hline $\mathrm{ATCO}$ & $\Lambda_{\mathrm{j}}\left|Q_{\mathrm{j}}\right|$ & atomic conductance. \\
\hline COEFF & $\alpha_{j i}$ & same as KOEFF, but in floating-point mode \\
\hline NA1, AN, NA2 & & Holerith headings, same as $A N 1$ and $A N 2$ in WRI 6 \\
\hline NAA1, AAN, NAA2 & & Holerith headings, same as AAN1 and AAN2 in WR16 \\
\hline IIT & & current number of time interval \\
\hline IPRINT. & . & index controlling the premature termination of a run \\
\hline
\end{tabular}

TABLE III. FORTRAN Notation for WR 17 and Subroutines as Faras Not Listed in Table II

In the remaining pages of this section, the FORTRAN source decks of program WR 17 and all necessary subroutines are listed. 
* F ANDKOBO

WATER RADIOLYSIS, WITH STEAOY STATE, FOR 'IBM-1620 K. SCHMIDT WR 17 DIMENSICNAC (24), C (24), ATCO(2) , EXT (22).RF (21), RK $(26)$ :M1 (25), M2(25) WR 17

1.KCEFF (21,25), JSK (24), ISK (25), CCMIN(24), CCMAX 24$)$, AM(4,5),

2 CCDT $(24,10): T(21)$ DIMENSI ON CSK (2,2:), A $(26,9), D R(21), G(22), S(22), C I(24)$,

1 IEQ $(21), N R S(5,21), C P(6), A A C(6), X N A X(6), X M I N(6), N A 1(24), N A 2(24), W R 17$

$2 \quad N A 41(6), N A A Z(6), \operatorname{SPSK}(2,21), A N(24), A A N(6)$

WR 17 COMMON AC, C, ATCO,EXT, RF, RK, MI, MZ,KOEFF, JSK, I SK, CCMIN, CCMAX, AM, DCDTWRI 1 , T, NC, NR, IFAIL, CONDI, ABSI,DT,LT, NPR, DTP,NCI, NCZ, NC3,LCYCL, ILINK, WRI7 2 IGROUP, IPRINT, TIME, IIT

EOUIVALENCE( AANI, ANI ), (AAN2,ANZ), (XMAX,CCMAX), (XMIN.CCMIN), (C.CI) WRII

1, (CP, ATCO), (DCDT,A)

CEFINE DISK $(7,1000)$

DO $610 \quad 1=1,4$

610 AM $(1, K)=0$.

$A M(1,1)=\operatorname{SGRTF}(2.25)$

$A_{N_{1}}(2,1)=1.9166667$

$A_{M} N_{1}(3,1)=2.2916667$

$A M(4,1)=2.6402778$

$A M(1,2)=1,-A M(1,1)$

$\triangle M(2,2)=-1.3333333$

$A M(3.2)=-2.4583 .333$

$\operatorname{AM}(4.2)=-3.8527773$

$\operatorname{AM}(2.3)=0.4166656$

$A M(3,3)=1.5416566$

$A M(4,3)=3.6333333$

$\operatorname{AM}(3,4)=-0.375$

$\operatorname{AM}(4.4)=-1.7694444$

$A M_{1}(4.5)=0.3486111$

1 READ 200 .NURUN

IF (NORUN) $600,600: 2$

2 PUNCH 300.NORUN

READ, COUNT AND PRINT CHEMICAL REACTIONS

3 DO 5 I = $1: 26$

$(I, K), K=1,3), A(I, 7), A(I, 4), A(I, 3), A(1,5), A(I, 9)$, $1 A(I, \zeta), R K(1)$

5 PUNCH301, (A $(I, K), K=1,3), A(I, 7), A(I, 4), A(I, 9), A(1,5), A(I, 9)$,

i A $(1,6)$, I, RK (I)

$6 \quad N R=1-1$

READ, COUNT AND PRINT SPECIES ETC.

PUNCH 302

DO $10 \mathrm{~J}=1,22$

READ $203, A C(J), G(J), S(J), C I(J), A T C O(J), E X T(J)$

9 IF $(A C(J)) 10,11,10$

1 C PUNCH 303,J.AC (J).G(J).S(J).CI (J). ATCO(J).EXT(J)

C $11 \mathrm{NC}=\mathrm{J}-1$

DEFINE SOME VALUES

$N C_{1}=N C+$

$N C 2=N C+2$

$\mathrm{NC3}=\mathrm{NC}+3$

I GROUP $=(N C 3+5) / 6$

DO $12 J=N C 1,24$

C

$12 C I(j)=0$.

COMPUTE AND PRINT INITIAL CONDUCTIVITY ANO OPTICAL DENSITY CONDI $=0$.

ABSI $=0$.

DO $100 \quad M=1$. NC

CONDI $=$ CONDI $+C I(M) * A T C O(M) * 0.001$

100 ABS I $=A E S I+C I(M) * E \times T(M)$

PUNCH 400 . CONDI. ABSI

C READ, COUNT AND FRINT DOSE RATE VALUES PUNCH: 304 PUNCH. 304

READ $205, T(K), O R(K), \operatorname{SPSK}(1, K), \operatorname{SPSK}(2, K), \operatorname{CSK}(1, K), \operatorname{CSK}(2, K)$

1 , (NRS $(M, K), M=1,5), I E Q(K)$

IF (ISG(K)) $: 4,615,14$

615 IF (T(K)) $14,14,616$

616 NTI $1=K$

IF (NTI)617.617,14

$617 \mathrm{NT} 1=1$

14 IF (T (K) $15,19,155$, DR $(K), \operatorname{SPSK}(1, K), \operatorname{SPSK}(2, K), \operatorname{CSK}(1, K), C S K(2, K)$

1 (NRS $(M, K), M=1,5), I E Q(K)$

19 READ OR DEFINE, AND PRINT, SOME PARAMETERS FOR COMPUTATION

READ 20 SACCFAC ANP OTPMIN OTMIN DTMAX DTMXEO IFR

READ $206, A C C F A C$ NP.OTPMIN, DTMIN.

619 AECFAC = O.

$62 C$ IF (DTPMIN) 621.621 .623

621 IF (NP-1) $622,622,623$

$622 \mathrm{NP}=40$

623 IF (DTMIN) $624,624,525$

624 DTMIN=T(NT1), 10000.

625 IF (DTMAX) $626,626,627$

625 IF (DTMAX) 626,626.

626 DTMAX $=T(T T T$ i ) /200. 620

627 IF (DTMXEO) $628,528.6$

628 JMXEG =T (NT) $/ 200$.

629 PUNCH $306, A C C F A C$.NP

$I F(I F R) 530.631 .530$

630 गUINEH 307

631 PUNCH 999 
C CALCULATE COEFFICIENTS OF DIFFERENTIAL EQUATIONS DO $30 \quad I=1$, NR I $S K(I)=0$ DO $30, J=1, N C$ $\operatorname{KOEFF}(J, I)=0$

22 KOEFF (J, $)=K O E F, 23,22,23$ $\operatorname{KOEFF}(J, I)=\operatorname{KOEFF}(J, I)-1$

¿3 IF $(A C(J)-A(1,2)) 25,24,25$.

$24 \operatorname{KOEFF}(J, I)=\operatorname{KOEFF}(J, I)-1$ $M 2(1)=J$

25 DO $30 \mathrm{~K}=3,5$

IF (AC (J)-A(I,K) $30,26,30$

26 KOEFF $(J, 1)=\operatorname{KOEFF}(J, 1)+1$

IF $(A(I, K+3)-0.20) 30.27 .30$ -

c

30 CONTINUE

INITIALIZE

DO $50 \quad J=1,24$

$C(J)=C I(J)$

CCMIN $(J)=0$.

$50 \mathrm{JSK}(J)=0$

TIME $=0$.

DT=DTMIN

$L T=0$

CALL STORE

C START SOLVING DIFFERENTIAL EQUATIONS

DO 120 IT $=1$. NT

I I T = IT

SKIPPING PROCEDURE

DO $450 \quad M=1,2$

IF (SPSK (M. IT) -SLA:JK) $431,450,431$

431 DO $435 \mathrm{~J}=1$, NC

IF (SPSK(M. IT)-AC ( J)) 435.432.435

432 JSK $(J)=J S K(J)+1$

IF (IEQ(IT) 723.723 .440

$723 \mathrm{C}(J)=C S K(M, I T)$

GO TO 450

$440 J \operatorname{SSK}(J)=J \operatorname{JSK}(J)+50$

435 GO TO 450

435 CONTINUE

CONTINUE
DO $470 \quad M=1.5$

IF (NRS (M.IT) $470 \cdot 470,455$

$455 \mathrm{I}=\mathrm{NRS}(\mathrm{M}, \mathrm{IT})$

I SK (I ) $=1.5 K($ I $)+1$

IF (IEQ(IT), 470.470 .533

633 ISK (I $)=I \cdot S K(I)+50$

470 CONTINUE

$M E Q=M E Q+I E Q(I T)$

$c$

IF (TIME-T(IT) $34,120,120$

34 DO 35 L $=1$.NC

$35 R F(L)=S(L)+(D R(I T) * G(L)) / 6.0231 E+25$

$L C Y C L=0$

I $L$ I NKT $=0$. . *DTMIN) $36 \cdot 636 \cdot 636$

$636 D T=D T * 0.5$

36 CALL CYCL 17

CALL EQUILIBRIUM ROUTINE

IF (MEQ $) 273.273 .74$

74 CALL EQUIL3

75 IF(IFAIL) I 74,174.575

575 PRINT 666 GO TO 130

174 LCYCL $=0$

273 I F (NPR-NP) $642,641,64$

641 IF (OTP-DTPMIN) 642,274.274

642 IF (TIME-T(I T) ) $175,274,274$

274 CALL STORE

CALL STORE

c

IF (LT+(IPRINT-1)*250)275:
IF(TIME-T(IT) $175.120 .1 \mathrm{ZO}$ REDETERMINE TIME INCREMENTS

175 DFOCMA $=0$.

DO $360 \quad L=1$, NC

IF (JSK (L) -1$) 643 \cdot 360.360$

643 DFDC $=0$.

DO $350, I=1$ i NR

$644 M 1 I=M 1(i)$

$M 2 I=M 2(I)$

COEFF $=$ KOEFF $(L \cdot)$

IF (MII -L) 646.645.546

645 DFDC $=D F D C+C O E F F * R K(I) * C(M 2 I)$

646 IF (M2 I -L) 350.647 .350

647. DFDC $=D F D C+C O E F F * R K(1) * C(M 11)$

350 CONTINUE

DFDCAB=ABSF (DFDC)

IF(DFDCAB-DFDCMA) 360.360 .355

355 DFDCMA = DFDCAB

WR $17 \quad 94$

WR17 95

WR $17 \quad 97$

WR 1798

WR 1799

WR 17100

WR 17101

WR 17 102

WR 17103

WR 17104

WR 17 1 105

WR 17106

WR 17108

WR 17109

WR 1717110

WR $17 \quad 112$

WR 17113

WR 17114

WR 17115

WR 17116

WR 171717

WR 17118

WR $17 \quad 120$

WR 17121

WR 17122

WR 17123

WR $17 \quad 124$

WR $17 \quad 125$

WR $17 \quad 126$

WR 171 1 7

WR17 129

WR 17130

WR $17 \quad 131$

WR $17 \quad 132$

WR $17 \quad 133$

WR $17 \quad 134$

WR $17 \quad 135$

WR $17 \quad 136$

WR $17 \quad 137$

$\begin{array}{lll}W R & 17 & 138\end{array}$

WR 17 I 39

WRI 7140

WR 17142

WR 17143

WR $17 \quad 144$

WR 17146

WR $17 \quad 147$

WR 17148

WR 17149

WR $17 \quad 150$

WR 17 i51

WR $17 \quad 152$

WR $17 \quad 153$

WR 17154

WR 17155

WR $17 \quad 156$

WR $17 \quad 157$

WR $17 \quad 158$

WR 17159

WR 17160

WR17 161

WR 17162

WR 17163

WR $17 \quad 154$

WR 17165

WR 17166

WR $17 \quad 167$

WR 17168

WRI 7169

WR 17170

WR $17 \quad 171$

WR $17 \quad 172$

WR 17173

WR 17174

WR 17175

WR 17176

WR $17 \quad 177$

WR $17 \quad 178$

$\begin{array}{lll}W R 17 & 179\end{array}$

WR $17 \quad 180$

WR $17 \quad 181$

WR 17 I 82

WR 17183

WR17 183

WR 17184

$\begin{array}{ll}\text { WR } 17 & 185 \\ \text { WR } 17 & 186\end{array}$ 


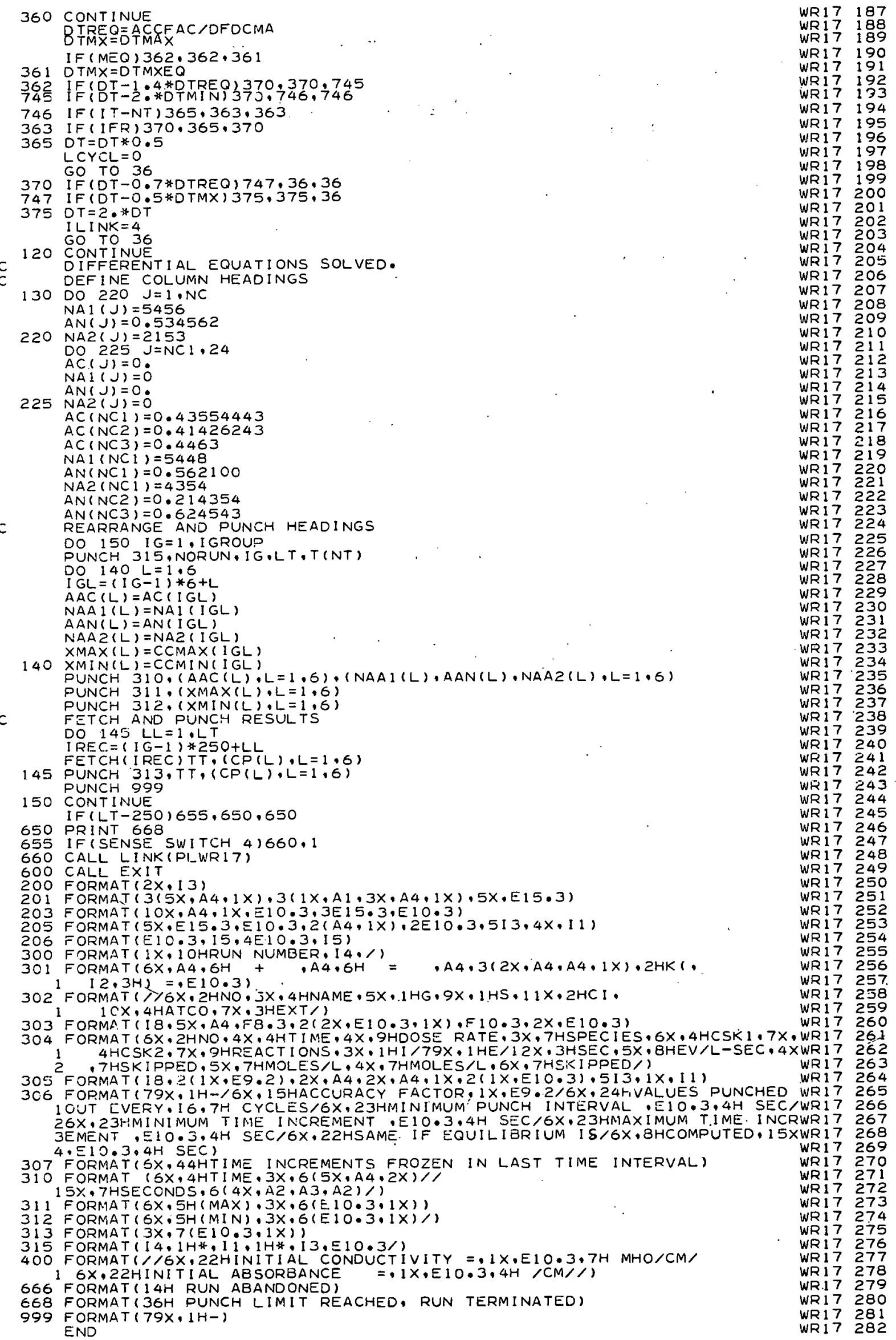


* FANDKO 804

CYCL17 0

SUBROUTINE CYCLIT

CYCL 171

DIMENSIONAC (24), C (24), ATCO(22), EXT(22), RF (21),RK(25), M1 (25), M2(25)CYCL 172

1 KOEFF(21,25), JSK $(24)$, ISK $(25)$, CCMIN $(24)$, CCMAX $(24)$, AM(4.5), CYCL17

2 DCDT $(24,10), T(21)$

DIMENSI ON PROD (25)

CYCLL 774

COMMON AC, C, ATCO, EXT, RF, RK, M1, M2,KOEFF, JSK, I SK, CCMIN, CCMAX, AM, DCDTCYCL 176

1 , T , NC, NR, I FAIL, CONDI , ABSI, DT, LT,NPR, DTP, NC1, NC2, NC3, LCYCL, ILINK, CYCL17 7

2 IGROUP, I PR INT . TIME , I T

DO 65 MCYCL $=1,2$

DO 65 NCYCL $=1,10$

$\angle C Y C L=L C Y C L+1$

IF (LCYCL -5) $38.38,37$

$37 \mathrm{LCYCL}=5$

c

START CYCLE OF CCIAPUTATION

$T I M E=T I M E+D T$

DO $51 \quad I=1$, NR

IF( ISK I I ) I52,52,51

$52 \mathrm{NI}=\mathrm{M} 1(1)$

$N 2=M 5(I)=C(N 1) * C(N 2) * R K(1)$

51 CONTINUE

DO $60 \mathrm{~L}=1$, NC

IF (JSK LL) $43,43,60$

43 DCDT $(L, N C Y C L)=R F(L)$

DO $42 \quad \mathrm{I}=1$, NR

IF(ISK(I) $44,44,42$

44 IF (KOEFF(L,I)) $41,42,4$

41 COEFF $=K O E F=$ ( $(L, 1)$

DCDT (L.NCYCL) =DCDT (L.NCYCL) +PROD (I)*COEFF

42 CONTINUE

$S L O P E=O$.

IF (ILINK) 54.54 .58

$c$

STANDARD ROUTINE FOR COMPUTING SLOPE

54 IF (LCYCL-1) 55.55 .56

GO TO 59

56 DO $57 \mathrm{~K}=1, \mathrm{LCYCL}$

INDK=NCYCL+1 $1-K-10 *((N C Y=L+10-K) / 10)$

57 SLOPE $=$ SLOPE + AM (LCYCL - 1, K) *DCDT ( L. INDK)

C

58 ID I $F=-1$

DO $158 \mathrm{~S} K=1,5$

IDIF=IDIF+I $+(K+I L I N K) / 7$

INDK $=N C Y C L+10-I D I F-10 *((N C Y C L+10-I D I F-1) / 10)$

158 SLOPE SLOPE +AM ( 4 , K) *DCDT (L, INDK)

59 IF (TIME-T(I T) ) 159,159.258

$258 C(L)=C(L)+S L O P E *$ (DT + T (IT) - TIME)

GO TO 60

$159 C(L)=C(L)+D T * S L O P E$

60 CONTINUE

IF (TIME-T (I T ) )61,259,259

259 TIME $=$ TIIT)

$L C Y C L=0$

GO TO 70

61 IF (ILINK) $63.63,64$

64 I L INK = I L I NK- I

$63 \mathrm{NPR}=\mathrm{NPR}+1$

$D T P=D T P+D T$

65 CONT INUE

RETURN

*FANDKOBO4

SUBROUTINE STORE

C CALCULATE CONDUCTIVITY AND ABSORBANCE. STORE SET CF OUTPUT VALUES DIMENSIONAC (24) O (24) ATCO (22) EXT(22),RF (21) RK (26) M1 (25) M2(25) STORE

1 KOEFF(2), 25$), J j K(24)$, ISK $(25), C C M I N(24), \operatorname{CCMAX}(24), A M(4,5)$,

1 DCDT $(24,10), T(21)$

COMMON AC, C. ATCO, EXT, RF, RK, MI, M2, KOEFF, JSK, I SK, CCMIN, CCMAX, AM,DCDTS 1 , T, NC, NR, IFAIL, CONDI , AESI, OT, LT, NPR, OTP,NCI, NC2, NC3,LCYCL, ILINK, 2 IGROUP, IPRINT, TIME, IT

CONDC $=-$ COND

$A B S C=-A B S$

$L T=L T+1$

IPRINT $=0$

DO 5 L $=1 \cdot N C$

CONDC $=C O N D C+C(L) * A T C O(L) * 0.001$

5 ABSC $=A B S C+C(L) * E \times T(L)$

$C(N C 1)=C O N D C$

$C(N C 2)=A B S C$

$C(N C 3)=D T$

DO. $25 \quad J=1 . N C 3$

IF $i C C M A X(J)-C(J), 10,15,15$

10 C CMAX $(J)=C(j)$

15 IF(CCMIN (J)-C(J)) $25,25.20$

$20 \operatorname{CCMIN}(J)=\operatorname{Cl}(J)$

25 CONT INUE

DO 30 I IG $=1 ; 1$ I ROUP

FIND(IREC)

CYCL 178

CYCLI7 9

CYCLITII

CYCL 1712

CYCL 1713

CYCL 1714

CYCL 1715

CYCL 1716

CYCL 1717

CYCLI719

CYCL 1720

CYCL 1721

CYCL 1722

CYCL 1733

CYCL 1724

CYCL 1725

CYCL 1726

CYCL 1728

CYCL 1729

CYCLI 1730

CYCL 1731

CYCL 1732

CYCLI733

CYCLI735

CYCL 1736

CYCL 1737

CYCL 1738

CYCLI739

CYCL 1740

CYCLI 741

CYCL 1743

CYCL 1744

CYCL 1745

CYCL 1746

CYCL 1748

CYCL 1749

CYCL1750

CYCL 1752

CYCL1753

CYCL 1754

CYCL 1755

CYCL 1756

CYCL 1757

CYCL 1758

CYCL 1759

CYCL 1760

CYCL 1761

CYCLI 732

CYCL 1763

STORE

STORE

STORE

STORE

TTORE

STORE 7

STORE 8

STORE 10

STORE 11

STORE 12

STORE

STORE I4

STORE 14

STORE 15

STORE. 16

STORE 18

STORE IO

STORE 20

STORE 21

STORE 11

STORE 23

STORE 24

STORE 25

STORE 26

STORE 27 


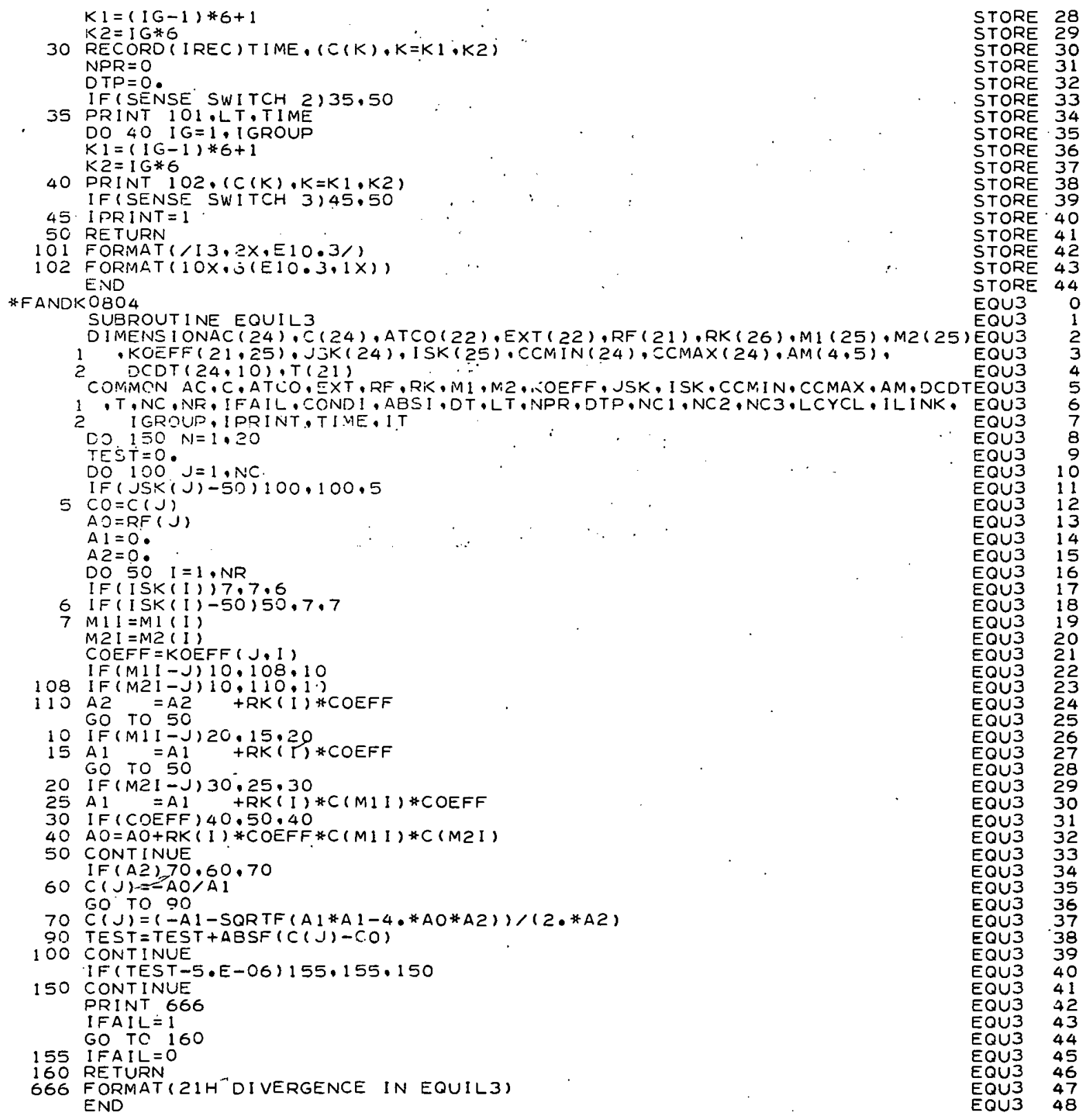




\section{ACKNOWLEDGMENTS}

I am grateful to Messrs. Leo C. Douglas, David M. Brooks, John A. Ohde, and Melvin R. Storm from Applied Mathematics Division for their help and advice in eliminating errors from the program. In particular, I am greatly indebted to Mr. Leo C. Douglas for his assistance in adapting the program to the IBM-1620 computer system, and for critically reading this paper and giving invaluable editorial advice.

\section{REFERENCES}

1. L. Collatz, Numerische Behandlung von Differentialgleichungen, Springer-Verlag, Berlin (1951), p. 44.

2. E. J. Hart, Radiation Chemistry of Aqueous Solutions, in Ann. Rev. Nucl. Sci. 15, 125(1965).

3. ANL Library Subroutine ANL Q050. 